\title{
Static Force Analysis of Foot of Electrically Driven Heavy-Duty Six-Legged Robot under Tripod Gait
}

\author{
Zhen Liu' ${ }^{1}$, Hong-Chao Zhuang ${ }^{2 *} \mathbb{D}$, Hai-Bo Gao' ${ }^{1}$ Zong-Quan Deng ${ }^{1}$ and Liang Ding ${ }^{1}$
}

\begin{abstract}
The electrically driven six-legged robot with high carrying capacity is an indispensable equipment for planetary exploration, but it hinders its practicability because of its low efficiency of carrying energy. Meanwhile, its load capacity also affects its application range. To reduce the power consumption, increase the load to mass ratio, and improve the stability of robot, the relationship between the walking modes and the forces of feet under the tripod gait are researched for an electrically driven heavy-duty six-legged robot. Based on the configuration characteristics of electrically driven heavy-duty six-legged, the typical walking modes of robot are analyzed. The mathematical models of the normal forces of feet are respectively established under the tripod gait of typical walking modes. According to the MATLAB software, the variable tendency charts are respectively gained for the normal forces of feet. The walking experiments under the typical tripod gaits are implemented for the prototype of electrically driven heavy-duty six-legged robot. The variable tendencies of maximum normal forces of feet are acquired. The comparison results show that the theoretical and experimental data are in the same trend. The walking modes which are most available to realize the average force of distribution of each foot are confirmed. The proposed method of analyzing the relationship between the walking modes and the forces of feet can quickly determine the optimal walking mode and gait parameters under the average distribution of foot force, which is propitious to develop the excellent heavy-duty multi-legged robots with the lower power consumption, larger load to mass ratio, and higher stability.
\end{abstract}

Keywords: Electrically driven, Heavy-duty six-legged robot, Tripod gait, Force of foot, Walking mode

\section{Introduction}

With the development of robotics, the autonomous mobile robot has been widely used [1, 2]. Intelligent [3, 4], high pass [5] and large load-ratio [6] robots have been gradually regarded as an important developing factor for the engineering of mobile robots. Based on the characteristics of common moving mechanisms, traditional mobile robots can be roughly divided into wheeled type, legged type, and wheel-legged type [7]. In the aspect of theoretical research and practical application, the legged robots relatively lag behind the wheeled ones [8], and the legged robots fall behind the wheeled ones in depth and

\footnotetext{
*Correspondence: zhuanghongchao_hit@163.com

${ }^{2}$ College of Mechanical Engineering, Tianjin University of Technology and Education, Tianjin 300222, China

Full list of author information is available at the end of the article
}

lack an extensive degree of research, especially the heavyduty multi-legged robots. The technology parameters of the heavy-duty multi-legged robots, such as BigDog [9], Ambler [10], ATHLETE [11, 12], and Dante II [13], concludes that the heavy-duty multi-legged robots have three major characteristics comparing to the non-heavyduty or small multi-legged robots; they are the larger volume, bigger mass, and larger load to mass ratio [14].

In nature, the coordinated movement of legs is used for the legged animals to realize their walking from the current position to goal position. That coordinated movement is often called the gait. With the increase of the number of legs for legged animals and multi-legged robots, their gait types also increase, and the corresponding gait planning method becomes more complex [15]. The conventional gait of the six-legged robot involves a tripod gait, a tetrapod gait, and a five-legged gait. The 
tripod gait is the fastest and most common for the sixlegged robots and hexapod [16].

The normal force of the foot is the main component, and it is often larger than the tangential force of the foot. From the perspective of posture and balance, the main factors influencing the poses of the multi-legged robots are pitch, roll, and vertical fluctuation. The factors are directly related to the normal force of the foot on every leg [17]. From the perspective of power consumption for the mobile system of robot, the power consumption of joint is primarily confirmed by the normal force of foot. The reason is that the mass and load of robot are counterpoised by the normal force of foot of each leg. Hence, it shows that the normal force of foot directly affects the posture and balance of robot and power consumption of mobile system. However, the normal force of the foot varies when the same leg is under different walking modes or gait. The walking mode and gait of robot are inherently associated with the normal force of the foot. Hence, the relationship between the gait and the normal force of foot will be important for reducing the power consumption of mobile systems and improving the load to mass ratio and stability of heavy-duty multi-legged robots.

Based on the effective poses of robot under the quadrangular gait, Zhuang et al. [18] presented a method to quickly obtain accurate the articulated torque by the normal force of foot for an electrically driven heavy-duty six-legged robot. The proposed method mainly involves the changes of rotational angles of the hip joint and knee joint. Li et al. [19] studied the optimal distribution of feet forces of multi-legged robots with uncertainties in both kinematics and dynamics. The analysis process is relatively complex because of referring to a large number of calculations and multiple algebraic derivations. Jiang et al. [20] introduced three new pseudo-inverse formulations for the real-time control of foot-force distribution of legged robot by avoiding foot-slip, minimizing the joint torques, and minimizing the joint work. The MAT$\mathrm{LAB}$ simulation of six-legged robot is only employed to compare locomotion performance with the truly optimal foot-force distributions. Xi and Remy [21] explored the potential of trajectory optimization for unspecified contact sequences to identify optimal gaits and motions of legged robots. However, the proposed method was only evaluated by a $1 \mathrm{D}$ hopper and a $2 \mathrm{D}$ bipedal robot. Agheli et al. [22] presented a solution of foot force distribution based on Newton-Euler equations of motion. Elfes et al. [23] employed a virtual second order mechanical system to define the foot force in the $z$ direction for the control of a multilegged autonomous explorer (MAX) robot. Montes and Armada [24] defined a virtual spring damper as the force of foot to evaluate the impedance controller of ROBOCLIMBER robot. Then, it can be found that many researchers mainly focus on the gait or force distribution for legged robots. There is less research on the relationship between the gait and the normal force of foot, especially for heavy-duty multi-legged robots.

Based on the above problems and our previous research [25-28], an electrically driven heavy-duty six-legged robot is considered to analyze its walking modes and the normal forces of its feet in different walking modes under the tripod gait. This paper is divided into six sections. In Section 2, the walking modes of the electrically driven heavy-duty six-legged robot are analyzed by the configuration of the robot. In Section 3, the static analysis of robot is performed. In Section 4, the theoretical analysis of the normal force of the foot is deduced in the typical walking mode under the tripod gait. In Section 5, the data of normal forces of the foot are collected from the walking experiments of the prototype under the tripod gait, and the experimental analysis is implemented. Then, the theoretical analysis and experimental analysis are mutually verified by comparing the theoretical calculation results with the experimental data for the normal force of the foot under the same variable and same walking mode of the tripod gait. According to the analysis of the walking mode and the normal force of the foot, the walking mode which is the most favorable to carry out the walk and average force distribution of the foot is obtained, and it provides support for future research on power consumption of mobile systems. In the final section, the conclusions are presented (Additional file 1).

\section{Configuration and Typical Walking Mode of Robot}

\subsection{Configuration of Robot}

In order to facilitate appellation in this paper, the electrically driven heavy-duty six-legged robot is called by the heavy-duty six-legged robot for short. Based on the structure of ambulacra of the hexapod, the leg of the heavy-duty six-legged robot can be designed. A single leg contains three electric driving joints: abductor joint, hip joint, and knee joint. In addition, the axis of abductor joint follows the direction of $z$, and the axes of hip joint and knee joint run parallel to the $y$-axis. The structure of the single leg of the heavy-duty six-legged robot is shown in Figure 1. The lengths of coxa, thigh, and shin are respectively set by $l_{\mathrm{c}^{\prime}} l_{\mathrm{t}}$, and $l_{\mathrm{s}^{\prime}} A_{i}, H_{i}$, and $K_{i}$ are respectively regarded as the abductor joint, hip joint, and knee joint of leg $i . \beta_{i}^{\prime}$ is defined as the angle between the coxa of leg $i$ and the thigh of leg $i$, and its range is form $-90^{\circ}$ to $90^{\circ}$. The angle $\beta_{i}$, whose range is limited to $0^{\circ}-150^{\circ}$, is between the coxa of leg $i$ and the shin of leg $i$. The positive and negative values of joint angles are correspondingly related to the positive and negative of articulated rotation directions. 


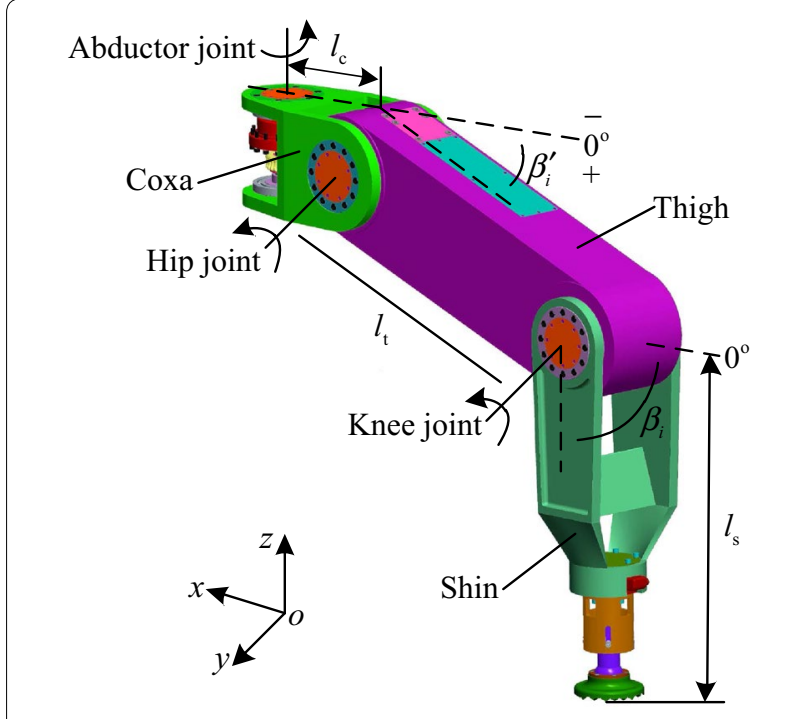

Figure 1 Structure of single leg of heavy-duty six-legged robot

To keep the characteristics of universal walking, configuration of the heavy-duty six-legged robot is designed as a regular polygon. Due to the static gait for the six-legged robot, the number of legs in the support phase varies from 3 to $6 . s_{u}$ and $t_{r}$ are respectively defined as the support phase of the legs and transfer phase of the legs rotating counterclockwise. The sets of the support phase and transfer phase are respectively defined by $s=\left(s_{1}, \ldots\right.$, $\left.s_{k}, \ldots, s_{u}\right)$ and $t=\left(t_{1}, \ldots, t_{e}, \ldots, t_{r}\right)$. Meanwhile, the constraint conditions should meet $3 \leq u \leq 6$ and $u+r=6$. The mechanism and its top view of the heavy-duty sixlegged robot are respectively shown in Figures 2 and 3.

In Figure 2, the body coordinate system of the robot is set by $\sum_{B}$, and is located at the center of the body. The principal vectors involving the gravity of the robot and principal moment are defined by $\boldsymbol{F}_{\mathrm{B}}=\left(F_{\mathrm{B} x}, F_{\mathrm{B} y}, F_{\mathrm{B} z}\right)^{\mathrm{T}}$

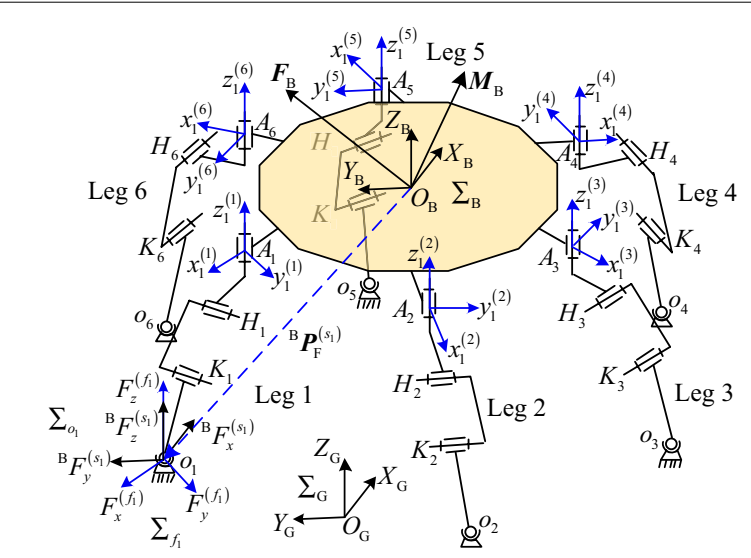

Figure 2 Mechanism of heavy-duty six-legged robot

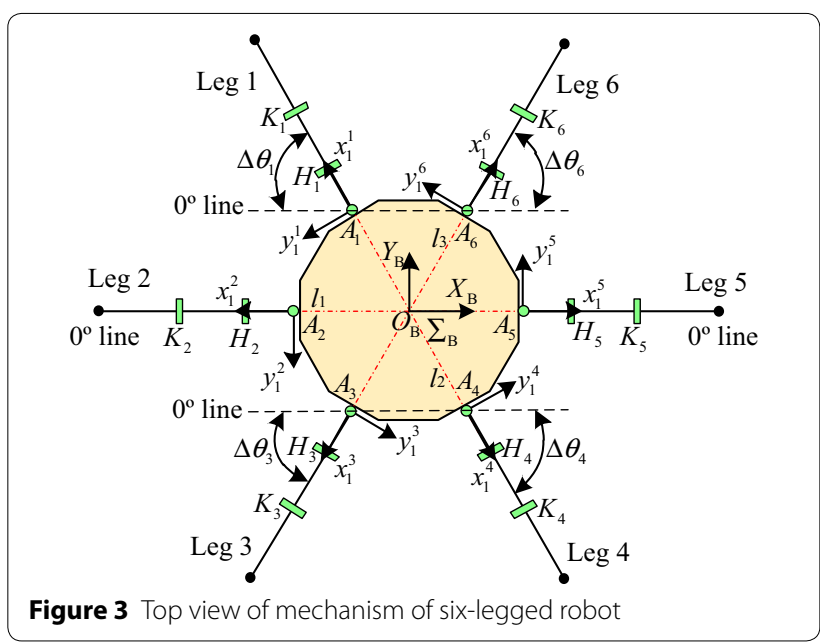

and $\boldsymbol{M}_{\mathrm{B}}=\left(M_{\mathrm{B} x}, M_{\mathrm{B} y}, M_{\mathrm{B} z}\right)^{\mathrm{T}} \cdot z_{1}^{(i)}$-axis in the abductor joint coordinate system of leg $i$ is parallel to the direction of $Z_{\mathrm{B}}$ in the body coordinate system. Positive direction of the $x_{1}^{(i)}$-axis in the abductor joint coordinate system of leg $i$ deviates from the coxa of leg $i$. The leg $i$ lies on the plan of $z_{1}^{(i)} x_{1}^{(i)}$. The positive directions of the abductor joint coordinate system $\sum_{A_{i}}$ of leg $i$ and the foot coordinate system $\sum_{f_{i}}$ of leg $i$ are same. The positive directions of the foot's coordinate system $\sum_{o_{i}}$ of leg $i$ are parallel to the positive direction of the body's coordinate system $\sum_{\mathrm{B}}$. The force of the leg $s_{k}$ in support phase can be divided into ${ }^{\mathrm{B}} F_{x}^{\left(s_{k}\right)},{ }^{\mathrm{B}} F_{y}^{\left(s_{k}\right)}$, and ${ }^{\mathrm{B}} F_{z}^{\left(s_{k}\right)}$ in the coordinate system $\sum_{o_{k}}$, and can be divided to $F_{x}^{\left(f_{k}\right)}, F_{y}^{\left(f_{k}\right)}$, and $F_{z}^{\left(f_{k}\right)}$ in the coordinate system $\sum_{f_{k}}$. The position vector of the foot at the end of the leg $s_{k}$ is set by ${ }^{\mathrm{B}} \boldsymbol{P}_{\mathrm{F}}^{\left(s_{k}\right)}$ in the body coordinate system. The body coordinate system connecting leg $i$ is defined as $\sum_{0_{i}}$. The coordinate system $\sum_{0_{i}}$ and coordinate system $\sum_{A_{i}}$ of abductor joint will coincide with each other when the rotating angle $\theta_{i}$ of abductor joint is zero degrees for leg $i$.

In Figure 3, the $0^{\circ}$ line is parallel to the $X_{\mathrm{B}}$ axis in the body coordinate system, and it intersects with the corresponding axes of joints. The included angle $\Delta \theta_{i}$, whose ranges is from $0^{\circ}$ to $60^{\circ}$, is defined as the initial angle of the abductor joint between the $0^{\circ}$ line and leg $i$, and the initial angle $\Delta \theta_{i}$ is used to set the initial position of abductor joint when the robot begins to walk. $\theta_{i}$ is defined as the rotation angle of the abductor joint of leg $i$ from the initial angle $\Delta \theta_{i}$. The initial angles $\Delta \theta_{2}$ and $\Delta \theta_{5}$ are always zero for leg 2 and leg 5 in this paper. The initial angles of abductor joints are $0^{\circ}-60^{\circ}$ for legs $1,3,4$, and 6 , and they are same when the heavy-duty six-legged robot begins to walk. 
As shown in Figure $3, \Phi_{i}$ is defined as the angle between the coordinate system $\sum_{0_{i}}$ and the coordinate system $\sum_{\mathrm{B}}$ for leg $i$. Therefore, the values of rotation angle $\Phi_{i}$ can be $120^{\circ}, 180^{\circ}, 240^{\circ}, 300^{\circ}, 360^{\circ}$, and $60^{\circ}$ for the legs $1,2,3,4,5$, and 6 , respectively. Then, the following equation can be obtained:

$$
{ }_{0}^{\mathrm{B}} \boldsymbol{R}^{(i)}=\operatorname{Rot}\left(z, \Phi_{i}\right)=\left(\begin{array}{ccc}
\cos \Phi_{i} & -\sin \Phi_{i} & 0 \\
\sin \Phi_{i} & \cos \Phi_{i} & 0 \\
0 & 0 & 1
\end{array}\right),
$$

The matrix ${ }_{\mathrm{o}}^{\mathrm{f}} \boldsymbol{R}^{(i)}$ can be deduced from the coordinate system $\sum_{A_{i}}$ of abductor joint to the coordinate system $\sum_{0_{i}}$ for leg $i$. Then

$$
{ }_{\mathrm{o}}^{\mathrm{f}} \boldsymbol{R}^{(i)}=\left({ }_{0}^{\mathrm{B}} \boldsymbol{R}^{(i) 0} \boldsymbol{R}^{(i)}\right)^{-1}=\left(\operatorname{Rot}\left(z, \Phi_{i}\right) \operatorname{Rot}\left(z, \theta_{i}\right)\right)^{\mathrm{T}} .
$$

\subsection{Typical Walking Mode of Robot}

Based on the configuration of heavy-duty six-legged robot, the tripod gait contains four typical walking modes: crab type, ant type, mixture type I, and mixture type II, as shown in Figure 4. In the tripod gait of the heavy-duty six-legged robot, legs 2, 4, and 6 located at the support phase are defined as the first group, and legs 1,3 , and 5 lying in the transfer phase are defined as the second group. However, legs of the support phase are analyzed in this paper.

In Figure $4, l_{1}, l_{2}$, and $l_{3}$ are defined as straight lines, and they are respectively orthogonal to the relevant axes of the abductor joints. In order to expediently analyze forces of the foot in typical walking modes of the tripod gait, the initial angles are respectively set by zero for legs $1,2,3,4,5$, and 6 . Meanwhile, $\theta_{i}$ is defined as the rotating angle of the abductor joint between the leg $i$ and $0^{\circ}$ line under an ant-type tripod gait. $\theta_{i}^{\prime}$ is defined as the rotating angle of the abductor joint between leg $i$ and the $0^{\circ}$ line under a crab-type tripod gait.

\section{Static Analysis of Robot}

The spatially parallel closed mechanism is combined by the legs of the support phase, body of robot, and ground. A passive sphere joint connects the foot and shin, and it can automatically adapt to the terrain ensuring that the foot completely contacts the ground. Hence, the moment does not exist between the ground and the foot, and the force only exists. The force analysis of heavy-duty six-legged robot is shown in Figure 2. In order to simply analyze, the force analysis of leg 1 is given in Figure $2 .{ }^{\mathrm{B}} \boldsymbol{P}_{\mathrm{F}}^{\left(s_{1}\right)}$ is defined as the position vector in the body coordinate system $\sum_{B}$ for leg 1 in the support phase. The principal vector of external force in robot system can be expressed as follows:

$$
\sum_{k=1}^{u}{ }^{\mathrm{B}} \boldsymbol{F}_{s_{k}}=\boldsymbol{J}_{\mathrm{F}}{ }^{\mathrm{B}} \boldsymbol{F}_{\mathrm{S}}=\left(\begin{array}{ccccccc}
1 & 0 & 0 & \cdots & 1 & 0 & 0 \\
0 & 1 & 0 & \cdots & 0 & 1 & 0 \\
0 & 0 & 1 & \cdots & 0 & 0 & 1
\end{array}\right)\left(\begin{array}{c}
{ }^{\mathrm{B}} F_{x}^{\left(s_{1}\right)} \\
{ }^{\mathrm{B}} F_{y}^{\left(s_{1}\right)} \\
{ }^{\mathrm{B}} F_{z}^{\left(s_{1}\right)} \\
\vdots \\
{ }^{\mathrm{B}} F_{x}^{\left(s_{u}\right)} \\
{ }^{\mathrm{B}} F_{y}^{\left(s_{u}\right)} \\
{ }^{\mathrm{B}} F_{z}^{\left(s_{u}\right)}
\end{array}\right)=\boldsymbol{F}_{\mathrm{B}},
$$

where $\boldsymbol{J}_{\mathrm{F}}$ is Jacobian matrix of force in the robot system, an identity matrix of $3 u \times 3 u,{ }^{\mathrm{B}} \boldsymbol{F}_{s_{k}}$ is force vector of foot in the coordinate system $\sum_{\mathrm{B}}$ or $\sum_{o_{k}}$ for leg $s_{k}$ in the support phase, ${ }^{\mathrm{B}} \boldsymbol{F}_{s_{k}}=\left({ }^{\mathrm{B}} F_{x}^{\left(s_{k}\right)}{ }^{\mathrm{B}} F_{y}^{\left(s_{k}\right)}{ }^{\mathrm{B}} F_{z}^{\left(s_{k}\right)}\right){ }^{\mathrm{T}},{ }^{\mathrm{B}} \boldsymbol{F}_{\mathrm{s}}$ is force matrix of the foot in the coordinate system $\sum_{B}$ for the leg in support phase, ${ }^{\mathrm{B}} \boldsymbol{F}_{\mathrm{S}}=\left({ }^{\mathrm{B}} \boldsymbol{F}_{s_{1}}{ }^{\mathrm{B}} \boldsymbol{F}_{s_{2}} \ldots{ }^{\mathrm{B}} \boldsymbol{F}_{s_{k}} \ldots{ }^{\mathrm{B}} \boldsymbol{F}_{s_{u}}\right)^{\mathrm{T}}$.

The expression can be written using the principal moment of external force in the robot's system. Then

$$
\boldsymbol{J}_{\mathrm{M}}{ }^{\mathrm{B}} \boldsymbol{F}_{\mathrm{s}}=\boldsymbol{M}_{\mathrm{B}},
$$

where $\boldsymbol{J}_{M}$ is position matrix in the coordinate system $\sum_{B}$ for the leg in support phase,

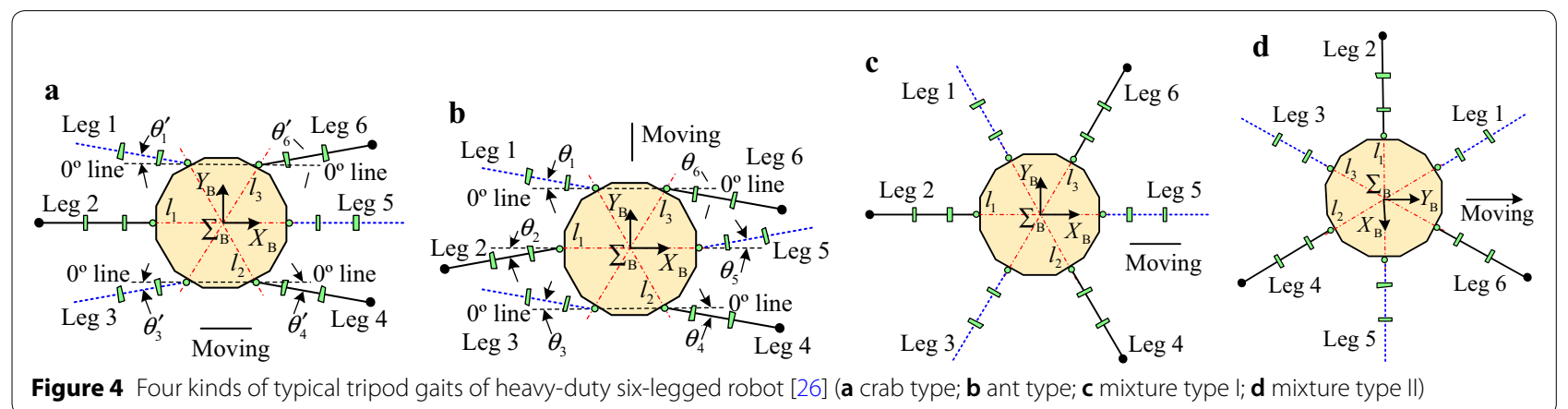




$$
\begin{aligned}
\boldsymbol{J}_{\mathrm{M}} & =\left(\begin{array}{cccc}
{ }^{\mathrm{B}} \boldsymbol{P}_{\mathrm{F}}^{\left(s_{1}\right)} \ldots & { }^{\mathrm{B}} \boldsymbol{P}_{\mathrm{F}}^{\left(s_{k}\right)} \ldots & \left.{ }^{\mathrm{B}} \boldsymbol{P}_{\mathrm{F}}^{\left(s_{u}\right)}\right)
\end{array}\right), \\
{ }^{\mathrm{B}} \boldsymbol{P}_{\mathrm{F}}^{\left(s_{k}\right)} & =\left(\begin{array}{ccc}
0 & -{ }^{\mathrm{B}} P_{\mathrm{F} z}^{\left(s_{k}\right)} & { }^{\mathrm{B}} P_{\mathrm{F} y}^{\left(s_{k}\right)} \\
{ }^{\mathrm{B}} P_{\mathrm{F} z}^{\left(s_{k}\right)} & 0 & -{ }^{\mathrm{B}} P_{\mathrm{F} x}^{\left(s_{k}\right)} \\
-{ }^{\mathrm{B}} P_{\mathrm{F} y}^{\left(s_{k}\right)} & { }^{\mathrm{B}} P_{\mathrm{F} x}^{\left(s_{k}\right)} & 0
\end{array}\right) .
\end{aligned}
$$

Based on Eqs. (3) and (4), the equilibrium matrix of generalized force can be obtained for the support phase of heavy-duty six-legged robot as follows:

$$
\begin{aligned}
\hat{\boldsymbol{J}}^{\mathrm{B}} \boldsymbol{F}_{\mathrm{S}} & =\left(\begin{array}{cccc}
\boldsymbol{I}_{3 \times 3} & \boldsymbol{I}_{3 \times 3} & \cdots & \boldsymbol{I}_{3 \times 3} \\
{ }^{\mathrm{B}} \boldsymbol{P}_{\mathrm{F}}^{\left(s_{1}\right)} & { }^{\mathrm{B}} \boldsymbol{P}_{\mathrm{F}}^{\left(s_{2}\right)} & \cdots & { }^{\mathrm{B}} \boldsymbol{P}_{\mathrm{F}}^{\left(s_{u}\right)}
\end{array}\right)\left(\begin{array}{c}
{ }^{\mathrm{B}} \boldsymbol{F}_{s_{1}} \\
{ }^{\mathrm{B}} \boldsymbol{F}_{s_{2}} \\
\vdots \\
{ }^{\mathrm{B}} \boldsymbol{F}_{S_{u}}
\end{array}\right) \\
& =\left(\begin{array}{c}
\boldsymbol{F}_{\mathrm{B}} \\
\boldsymbol{M}_{\mathrm{B}}
\end{array}\right)=\hat{\boldsymbol{A}} .
\end{aligned}
$$

where $\hat{\boldsymbol{J}}$ is equivalent matrix of the foot position in the support phase, $\boldsymbol{I}_{3 \times 3}$ is the identity matrix of $3 \times 3$.

The force of the foot is zero when the leg is in transfer phase, and its matrix expression can be written using the body coordinate system $\sum_{\mathrm{B}}$. Then,

$$
{ }^{\mathrm{B}} \boldsymbol{F}_{\mathrm{t}}=\left({ }^{\mathrm{B}} \boldsymbol{F}_{t_{1}}{ }^{\mathrm{B}} \boldsymbol{F}_{t_{2}} \cdots{ }^{\mathrm{B}} \boldsymbol{F}_{t_{e}} \cdots{ }^{\mathrm{B}} \boldsymbol{F}_{t_{r}}\right)^{\mathrm{T}}=0,
$$

where ${ }^{\mathrm{B}} \boldsymbol{F}_{t_{e}}$ is force vector of foot in the coordinate system $\sum_{\mathrm{B}}$ or $\sum_{o_{k}}$ for leg $t_{e}$ in the transfer phase,

$$
{ }^{\mathrm{B}} \boldsymbol{F}_{t_{e}}=\left({ }^{\mathrm{B}} F_{x}^{\left(t_{e}\right)}{ }^{\mathrm{B}} F_{y}^{\left(t_{e}\right)} \mathrm{B}^{\mathrm{B}} F_{z}^{\left(t_{e}\right)}\right)^{\mathrm{T}} \text {. }
$$

Based on Eqs. (5) and (6), the equilibrium matrix of general force can be written for the system of heavy-duty six-legged robot as follows:

$$
\left(\begin{array}{cc}
\hat{\boldsymbol{J}} & \boldsymbol{O}_{6 \times 3 r} \\
\boldsymbol{O}_{3 r \times 3 u} & \boldsymbol{I}_{3 r \times 3 r}
\end{array}\right)\left(\begin{array}{c}
{ }^{\mathrm{B}} \boldsymbol{F}_{\mathrm{s}} \\
{ }^{\mathrm{B}} \boldsymbol{F}_{\mathrm{t}}
\end{array}\right)=\left(\begin{array}{c}
\hat{\boldsymbol{A}} \\
0
\end{array}\right) .
$$

where $\boldsymbol{O}$ is zero matrix.

Based on Figure 2 and Eq. (2), the mathematical relationship of force of foot in the coordinate system $\sum_{o_{k}}$ and the coordinate system $\sum_{f_{k}}$ can be written for leg $s_{k}$ in the support phase as follows:

$$
\left(\begin{array}{l}
F_{x}^{\left(f_{k}\right)} \\
F_{y}^{\left(f_{k}\right)} \\
F_{z}^{\left(f_{k}\right)}
\end{array}\right)={ }_{\mathrm{o}}^{\mathrm{f}} \boldsymbol{R}^{\left(s_{k}\right)}\left(\begin{array}{l}
{ }^{\mathrm{B}} F_{x}^{\left(s_{k}\right)} \\
{ }^{\mathrm{B}} F_{y}^{\left(s_{k}\right)} \\
{ }^{\mathrm{B}} F_{z}^{\left(s_{k}\right)}
\end{array}\right) .
$$

\section{Force Theoretical Analysis of Foot under Gait of Robot}

The normal force of the foot is generally much larger than the tangential force. The normal force of the foot is not only a key factor on influencing the position and balance of the robot as well as power consumption of the mobile system, but also a principle balance force to equilibrate the weight of the robot and its load. Thus, to easily calculate the normal force of the foot using the mechanical equilibrium equation, the tangential force of the foot can be ignored in the theoretical mechanical analysis of the foot force under the robot's gait. The tripod gait is a common gait, and it is also the fastest gait for the six-legged robot. In this section, the normal force of the foot in the support phase is only analyzed under the tripod gait, and the step pitch and initial angle are changing.

For the same leg in the support phase, its normal force varies under the same gait and different terrain. It shows that the terrain affects the value of the foot's normal force, and it is difficult to reproduce the same relation between the gait and the normal force of the foot in complex terrain for the same supporting leg. That is to say, the values of the normal forces of the foot are difference when the robot repetitiously traverses the same terrain under the same gait. However, it is difficult to obtain the real relation between the gait and the normal force of the foot. Hence, the flat ground is used to research the relation above, and it is useful to lay the foundation for analyzing that relation on the complex terrain.

The walking speed keeps stable when the heavy-duty six-legged robot linearly walks. The distance of the mass center of body to the ground is a constant. The foot's projective tracks for every leg and mass center of the body are parallel to each other. It is assumed that the robot cannot bear the additional principal vector and principal moment expect for the masses of robot and cargoes. Then, the principal vector and principal moment of robot should meet:

$$
\left(\begin{array}{c}
\boldsymbol{F}_{\mathrm{B}} \\
\boldsymbol{M}_{\mathrm{B}}
\end{array}\right)=\left(\begin{array}{llllll}
0 & 0 & m_{\mathrm{L}} g+m_{\mathrm{R}} g & 0 & 0 & 0
\end{array}\right)^{\mathrm{T}},
$$

where $m_{\mathrm{L}}$ is the mass of the robot, $m_{\mathrm{R}}$ is the mass of cargo carried by the robot.

The tripod gait is used for the heavy-duty six-legged robot. Then, the support phase involves legs 2,4 , and 6 , and the transfer phase involves legs 1,3 , and 5 . The normal force of the foot in the support phase is restricted by the mass $m_{\mathrm{L}}$ of the robot and mass $m_{\mathrm{R}}$ of cargo. When 
the tangential force of the foot is ignored, the expression can be obtained for the normal force of the foot in the support phase as follows:

$$
\left(\begin{array}{l}
{ }^{\mathrm{B}} \boldsymbol{F}_{s_{2}} \\
{ }^{\mathrm{B}} \boldsymbol{F}_{s_{4}} \\
{ }^{\mathrm{B}} \boldsymbol{F}_{s_{6}}
\end{array}\right)^{\mathrm{T}}=\left(\begin{array}{lllllllllll}
0 & 0 & { }^{\mathrm{B}} F_{z}^{\left(s_{2}\right)} & 0 & 0 & { }^{\mathrm{B}} F_{z}^{\left(s_{4}\right)} & 0 & 0 & { }^{\mathrm{B}} F_{z}^{\left(s_{6}\right)}
\end{array}\right) .
$$

Based on Eq. (5), the equilibrium matrix of general forces in the support phase can be deduced for the heavy-duty six-legged robot as follows:

$$
\hat{\boldsymbol{J}}^{\mathrm{B}} \boldsymbol{F}_{\mathrm{S}}=\left(\begin{array}{ccc}
\boldsymbol{I}_{3 \times 3} & \boldsymbol{I}_{3 \times 3} & \boldsymbol{I}_{3 \times 3} \\
{ }^{\mathrm{B}} \boldsymbol{P}_{\mathrm{F}}^{\left(s_{2}\right)} & { }^{\mathrm{B}} \boldsymbol{P}_{\mathrm{F}}^{\left(s_{4}\right)} & { }^{\mathrm{B}} \boldsymbol{P}_{\mathrm{F}}^{\left(s_{6}\right)}
\end{array}\right)\left(\begin{array}{c}
{ }^{\mathrm{B}} \boldsymbol{F}_{s_{2}} \\
{ }^{\mathrm{B}} \boldsymbol{F}_{s_{4}} \\
{ }^{\mathrm{B}} \boldsymbol{F}_{s_{6}}
\end{array}\right)=\left(\begin{array}{c}
\boldsymbol{F}_{\mathrm{B}} \\
\boldsymbol{M}_{\mathrm{B}}
\end{array}\right) .
$$

Equations (4), (9), and (10) are respectively substituted into Eq. (11), and the equilibrium equations of robot can be deduced as follows:

$$
\left\{\begin{array}{l}
{ }^{\mathrm{B}} F_{z}^{\left(s_{2}\right)}+{ }^{\mathrm{B}} F_{z}^{\left(s_{4}\right)}+{ }^{\mathrm{B}} F_{z}^{\left(s_{6}\right)}=m_{\mathrm{L}} g+m_{\mathrm{R}} g, \\
{ }^{\mathrm{B}} P_{\mathrm{F} y}^{\left(s_{2}\right) \mathrm{B}} F_{z}^{\left(s_{2}\right)}+{ }^{\mathrm{B}} P_{\mathrm{Fy}}^{\left(s_{4}\right) \mathrm{B}} F_{z}^{\left(s_{4}\right)}+{ }^{\mathrm{B}} P_{\mathrm{F} y}^{\left(s_{6} \mathrm{~B}\right.} F_{z}^{\left(s_{6}\right)}=0, \\
{ }^{\mathrm{B}} P_{\mathrm{F} x}^{\left(s_{2}\right) \mathrm{B}} F_{z}^{\left(s_{2}\right)}+{ }^{\mathrm{B}} P_{\mathrm{F} x}^{\left(s_{4}\right) \mathrm{B}} F_{z}^{\left(s_{4}\right)}+{ }^{\mathrm{B}} P_{\mathrm{F} x}^{\left(s_{6}\right) \mathrm{B}} F_{z}^{\left(s_{6}\right)}=0 .
\end{array}\right.
$$

When the heavy-duty six-legged robot begins to walk, the initial angles of abductor joints are equal for legs $1,3,4$, and 6, and the initial angles of abductor joints of legs 2 and 5 are set as the zero degrees. Therefore, the relations of the initial angles are $\Delta \theta_{1}=\Delta \theta_{3}=\Delta \theta_{4}=\Delta \theta_{6}$ and $\Delta \theta_{2}=\Delta \theta_{5}=0^{\circ}$. $L_{\mathrm{p} i}^{\prime}$ is defined as the projective length of leg $i$ in the support phase on the ground, and it is the initial offset. To simplify the analysis, the variables $\Delta \theta$ and $L_{\mathrm{ps}}^{\prime}$ are introduced. Then, the following mathematical relationships can be obtained:

$$
\left\{\begin{array}{l}
\Delta \theta_{1}=\Delta \theta_{3}=\Delta \theta_{4}=\Delta \theta_{6}=\Delta \theta \\
L_{\mathrm{P} 2}^{\prime}=L_{\mathrm{P} 4}^{\prime}=L_{\mathrm{P} 6}^{\prime}=L_{\mathrm{PS}}^{\prime}
\end{array}\right.
$$

\subsection{Theoretical Analysis of Normal Force of Foot under Ant-type Tripod Gait}

The support phase is shown in Figure 5, and the ant-type tripod gait is used for the heavy-duty six-legged robot. In Figure 5, the robot walks along the direction of $Y_{\mathrm{B}}$ axis. $s_{\mathrm{u}}$ and $s_{\mathrm{d}}$ are respectively defined as the upper point and lower point for the legs in support phase. The distance from $s_{\mathrm{u}}$ to $s_{\mathrm{d}}$ is defined by $s$, and it is also the step pitch in this paper. The coordinate of foot is expressed by $\left({ }^{\mathrm{B}} P_{\mathrm{F} x}^{\left(s_{k}\right)},{ }^{\mathrm{B}} P_{\mathrm{F} y}^{\left(s_{k}\right)},{ }^{\mathrm{B}} P_{\mathrm{F} z}^{\left(s_{k}\right)}\right)$

in the body coordinate system $\sum_{\mathrm{B}}$ for leg $s_{k}$.

Based on Figure 5, the coordinates of the legs' feet in the support phase can be obtained along the $x$ direction of the body coordinate system $\sum_{\mathrm{B}}$ as follows:

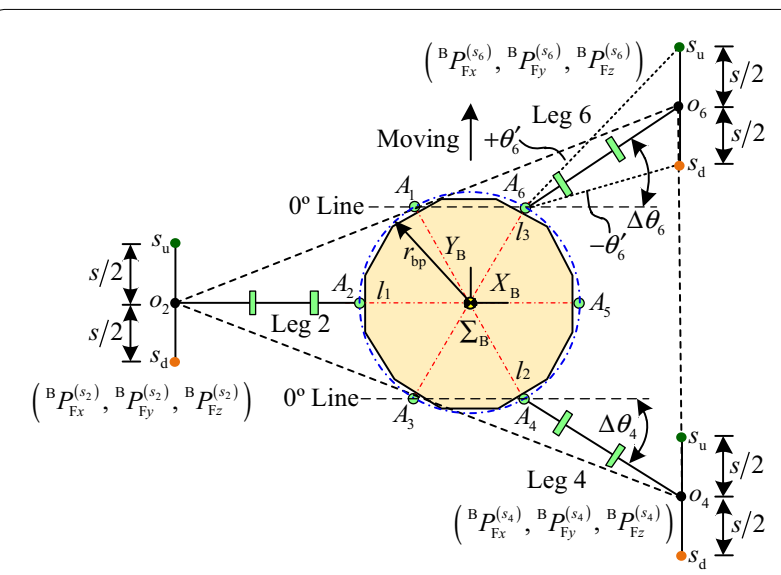

Figure 5 Support phase of heavy-duty six-legged under ant-type tripod gait

$$
\left\{\begin{array}{l}
{ }^{\mathrm{B}} P_{\mathrm{F}}^{\left(s_{2}\right)}=-\left(r_{\mathrm{bp}}+L_{\mathrm{P} 2}^{\prime}\right), \\
{ }^{\mathrm{B}} P_{\mathrm{F} x}^{\left(s_{4}\right)}=r_{\mathrm{bp}} \cos 60^{\circ}+L_{\mathrm{P} 4}^{\prime} \cos \left(\Delta \theta_{4}\right), \\
{ }^{\mathrm{B}} P_{\mathrm{F} x}^{\left(s_{6}\right)}=r_{\mathrm{bp}} \cos 60^{\circ}+L_{\mathrm{P} 6}^{\prime} \cos \left(\Delta \theta_{6}\right) .
\end{array}\right.
$$

When the body of the robot walks forward using step pitch $s$, the foot in the support phase relatively moves back distance $s$. The gravity center of the robot and support points of the legs respectively move from the upper point $s_{\mathrm{u}}$ to the lower point $s_{\mathrm{d}}$. Then, the coordinates of the feet at the lowest point $s_{\mathrm{d}}$ can be respectively deduced along the $y$ direction in the body coordinate system $\sum_{\mathrm{B}}$ for legs 2,4 , and 6; they are shown as follows:

$$
\left\{\begin{array}{l}
{ }^{\mathrm{B}} P_{\mathrm{F} y}^{\left(s_{2}\right)}=-s / 2, \\
{ }^{\mathrm{B}} P_{\mathrm{F} y}^{\left(s_{4}\right)}=-\left(r_{\mathrm{bp}} \sin 60^{\circ}+L_{\mathrm{P} 4}^{\prime} \sin \left(\Delta \theta_{4}\right)\right)-s / 2, \\
{ }^{\mathrm{B}} P_{\mathrm{F} y}^{\left(s_{6}\right)}=\left(r_{\mathrm{bp}} \sin 60^{\circ}+L_{\mathrm{P} 6}^{\prime} \sin \left(\Delta \theta_{6}\right)\right)-s / 2 .
\end{array}\right.
$$

Equations (14) and (15) can be substituted into Eq. (12). The mathematical models of the normal forces of feet can be respectively deduced for the legs 2,4 , and 6 . Then

$$
\left\{\begin{array}{l}
{ }^{\mathrm{B}} F_{z}^{\left(s_{2}\right)}=\frac{r_{\mathrm{bp}}+2 L_{\mathrm{PS}}^{\prime} \cos (\Delta \theta)}{\mathrm{Q}_{3}}\left(m_{\mathrm{L}} g+m_{\mathrm{R}} g\right), \\
{ }^{\mathrm{B}} F_{z}^{\left(s_{4}\right)}=\frac{Q_{1}-Q_{2}}{Q_{3} \times Q_{4}}\left(m_{\mathrm{L}} g+m_{\mathrm{R}} g\right), \\
{ }^{\mathrm{B}} F_{z}^{\left(s_{6}\right)}=\frac{Q_{1}+Q_{2}}{Q_{3} \times Q_{4}}\left(m_{\mathrm{L}} g+m_{\mathrm{R}} g\right) .
\end{array}\right.
$$

where

$$
\left\{\begin{array}{l}
Q_{1}=\left(r_{\mathrm{bp}}+L_{\mathrm{PS}}^{\prime}\right)\left(\sqrt{3} r_{\mathrm{bp}}+2 L_{\mathrm{PS}}^{\prime} \sin (\Delta \theta)\right) \\
Q_{2}=\left(3 r_{\mathrm{bp}} / 2+L_{\mathrm{PS}}^{\prime}+L_{\mathrm{PS}}^{\prime} \cos (\Delta \theta)\right) s \\
Q_{3}=3 r_{\mathrm{bp}}+2 L_{\mathrm{PS}}^{\prime}+2 L_{\mathrm{PS}}^{\prime} \cos (\Delta \theta) \\
Q_{4}=\sqrt{3} r_{\mathrm{bp}}+2 L_{\mathrm{PS}}^{\prime} \sin (\Delta \theta) .
\end{array}\right.
$$


When the feet in the support phase are located at the upper point $s_{\mathrm{u}}$ for legs 2,4 , and 6 , their coordinates along the $y$ direction in body coordinate $\sum_{\mathrm{B}}$ can be obtained by changing the $s$ to $-s$ in Eq. (15), and their normal forces can be also obtained by setting $s$ to the $-s$ in Eq. (16). Then, the mathematical models of the normal forces of the feet are not given for legs 2, 4, and 6 in this paper.

The step pitch $s$, height of body $h$, and initial offset $L^{\prime}$ PS are respectively set by $0.4 \mathrm{~m}, 0.5 \mathrm{~m}$, and $0.68 \mathrm{~m}$ for the heavy-duty six-legged robot, when the feet in the support phase move from the upper point $s_{\mathrm{u}}$ to the lower point $s_{\mathrm{d}}$. The ranges of the initial angles of the abductor joints are from $0^{\circ}$ to $60^{\circ}$ for legs $1,3,4$, and 6 . The radius $r_{\mathrm{bp}}$ of the body is introduced in Eq. (16). Then, MATLAB software is used to compile programs for analyzing the normal forces of feet of the support phase under the ant-type tripod gait. The variable tendency charts of the normal forces of feet are obtained and respectively shown in Figures 6,7 , and 8 for legs 2,4 , and 6 .

Based on Figure 6, the normal force of the foot of leg 2 gradually decreases from $1478 \mathrm{~N}$ to $1098 \mathrm{~N}$, when the initial angle $\Delta \theta$ of abductor joint varies from $0^{\circ}$ to $60^{\circ}$. The normal force of the foot of leg 2 is a constant with a change of step pitch $s$. When the initial angle $\Delta \theta$ of the abductor joint is $20^{\circ}$, the normal force of the foot is about $1442 \mathrm{~N}$ for leg 2.

Based on Figure 7 , with the initial angle $\Delta \theta$ varying from $0^{\circ}$ to $60^{\circ}$, it shows that the variable tendency of the foot's normal force overall presents from augmentation to a decrease for the leg 4 , when the step pitch $s$ is between $0 \mathrm{~m}$ to $0.2 \mathrm{~m}$. In addition, the normal force of the foot of leg 4 gradually increases when the step pitch $s$ is between $0.2 \mathrm{~m}$ to $0.4 \mathrm{~m}$. It also shows that the normal force of the foot overall decreases for leg 4 , when the initial angle $\Delta \theta$ is a fixed value and the range of step pitch $s$ is from $0 \mathrm{~m}$ to $0.4 \mathrm{~m}$. For the foot's normal force of leg 4 , the maximum

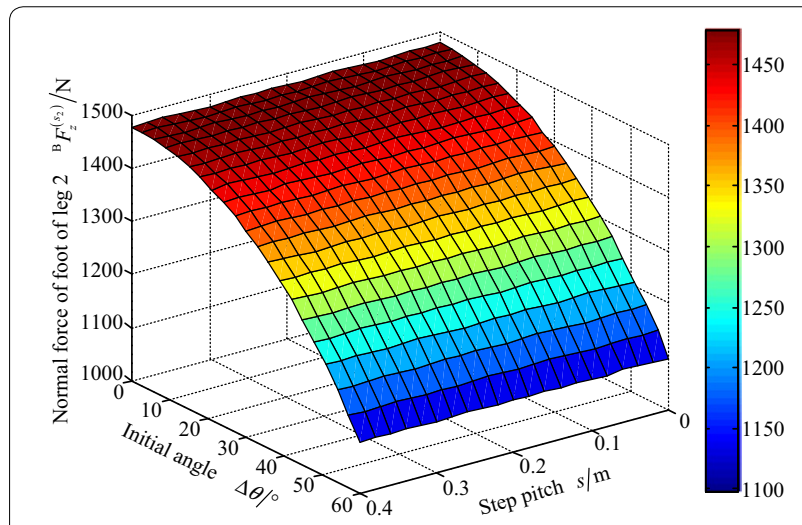

Figure 6 Variable tendency chart of normal force of foot for leg 2 with changes in $\Delta \theta$ and $s$ under ant-type tripod gait

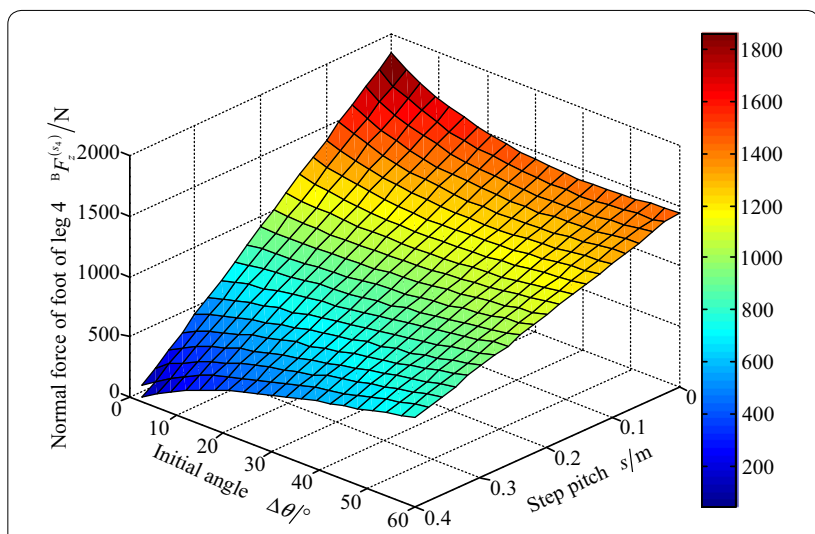

Figure 7 Variable tendency chart of normal force of foot for leg 4 with changes in $\Delta \theta$ and $s$ under ant-type tripod gait

value is $1858 \mathrm{~N}$ when the step pitch $s$ and initial angle $\Delta \theta$ are zero, and the minimum value is $45.62 \mathrm{~N}$ when the step pitch $s$ is $0.4 \mathrm{~m}$ and the initial angle $\Delta \theta$ is $3^{\circ}$.

Based on Figure 8 , with the initial angle $\Delta \theta$ varying from $0^{\circ}$ to $60^{\circ}$, it shows that the variable tendency of the normal force of the foot overall presents from a decrease to augmentation for the leg 6 , when the step pitch $s$ is between $0.2 \mathrm{~m}$ to $0.4 \mathrm{~m}$. The normal force of the foot of leg 6 gradually increases when the step pitch $s$ is between $0 \mathrm{~m}$ to $0.2 \mathrm{~m}$. It can be found that the normal force of the foot increases overall for leg 6 , when the initial angle $\Delta \theta$ is a fixed value and the range of step pitch $s$ is from $0 \mathrm{~m}$ to $0.4 \mathrm{~m}$. For the foot's normal force of leg 6, its maximum value is $1858 \mathrm{~N}$ when the step pitch $s$ and initial angle $\Delta \theta$ are zero, its minimum value is $45.62 \mathrm{~N}$ when the step pitch $s$ is $0 \mathrm{~m}$ and the initial angle $\Delta \theta$ is $3^{\circ}$, and its value is $1098 \mathrm{~N}$ when the step pitch $s$ is $0.2 \mathrm{~m}$ and the initial angle $\Delta \theta$ is $60^{\circ}$.

According to Figures 6, 7, and 8, the curves of the maximum normal forces of feet are obtained for legs 2,4 , and 6 with the varying of the initial angle $\Delta \theta$ and step pitch

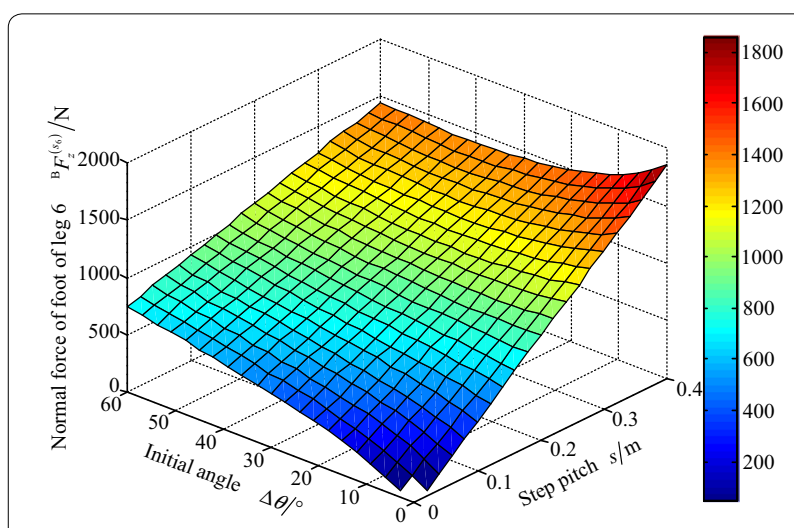

Figure 8 Variable tendency chart of normal force of foot for leg 6 with changes in $\Delta \theta$ and $s$ under ant-type tripod gait 


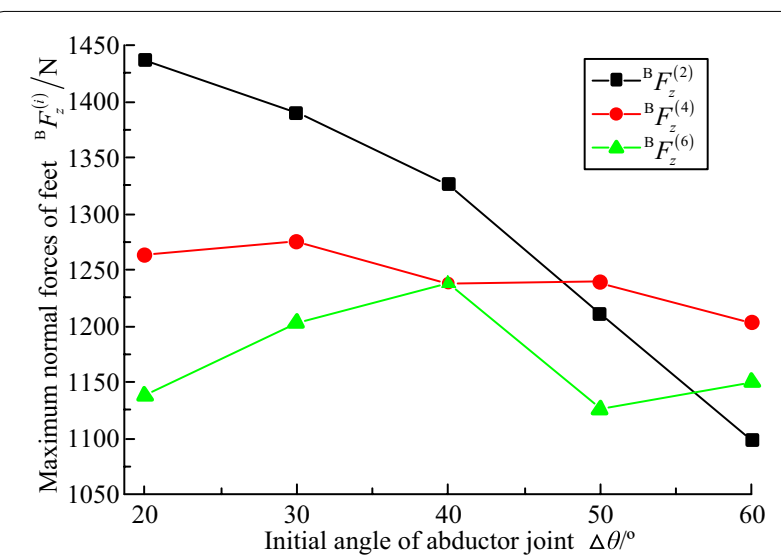

Figure 9 Curves of maximum normal forces of feet under $s=0.4 \mathrm{~m}$, $20^{\circ} \leq \Delta \theta \leq 60^{\circ}$, and ant-type tripod gait

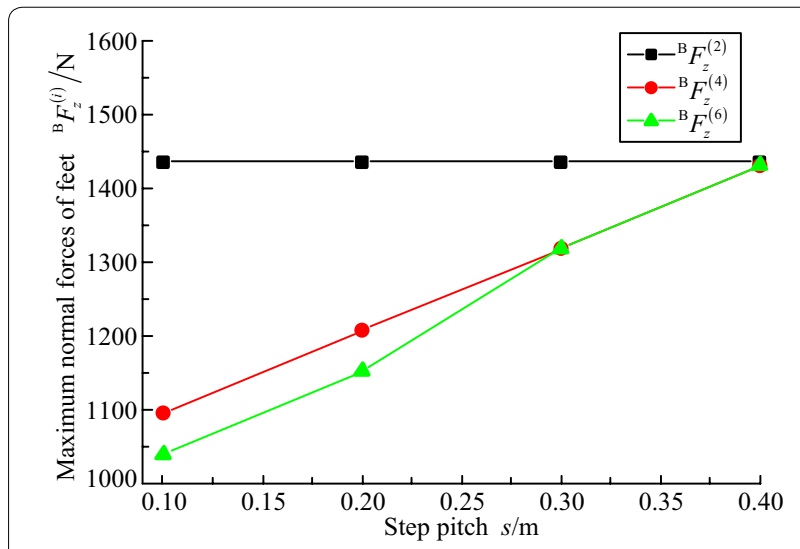

Figure 10 Curves of maximum normal forces of feet under $0.1 \mathrm{~m} \leq s \leq 0.4 \mathrm{~m}, \Delta \theta=20^{\circ}$, and ant-type tripod gait

$s$. When $s=0.4 \mathrm{~m}$ and $20^{\circ} \leq \Delta \theta \leq 60^{\circ}$, the curves of the maximum normal forces of feet are shown in Figure 9. When $0.1 \mathrm{~m} \leq s \leq 0.4 \mathrm{~m}$ and $\Delta \theta=20^{\circ}$, the curves of the maximum normal forces of feet are shown in Figure 10. When $0.1 \mathrm{~m} \leq s \leq 0.4 \mathrm{~m}$ and $\Delta \theta=60^{\circ}$, the curves of the maximum normal forces of feet are shown in Figure 11.

According to Figure 9, when the step pitch $s$ is $0.3 \mathrm{~m}$ and the initial angle $\Delta \theta$ varies from $20^{\circ}$ to $60^{\circ}$, it can be found that the maximum normal force of the foot of leg 2 gradually reduces, and the maximum normal forces of feet are from augmentation to a decrease for the legs 4 and 6 .

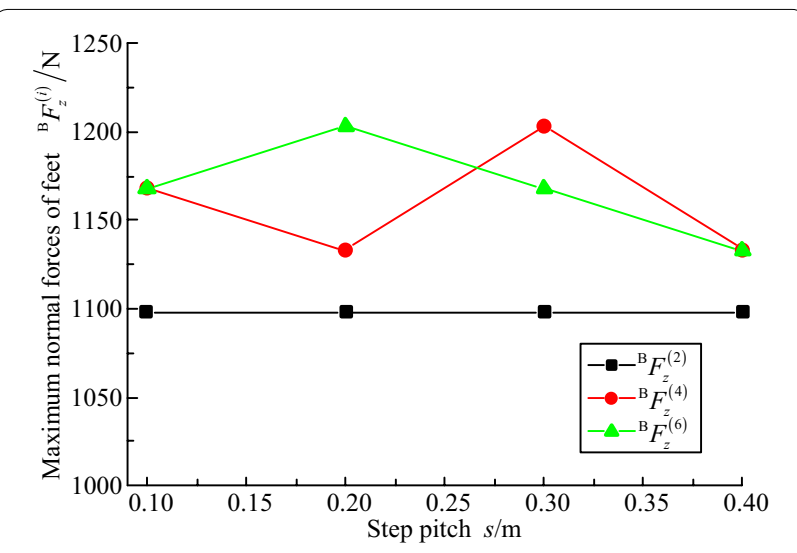

Figure 11 Curves of maximum normal forces of feet under $0.1 \mathrm{~m} \leq s \leq 0.4 \mathrm{~m}, \Delta \theta=60^{\circ}$, ant-type tripod gait

Based on Figure 10, when the step pitch $s$ varies from $0.1 \mathrm{~m}$ to $0.4 \mathrm{~m}$ and the initial angle $\Delta \theta$ is $20^{\circ}$, it shows that the maximum normal force of the foot is a constant for the leg 2, and the maximum normal forces of feet gradually decreases for the legs 4 and 6 .

According to Figure 11, when the step pitch $s$ changes from $0.1 \mathrm{~m}$ to $0.4 \mathrm{~m}$ and the initial angle $\Delta \theta$ is $60^{\circ}$, it can be found that the maximum normal force of the foot remains constant for the leg 2, the maximum normal force of the foot first decreases, then increases, and finally decreases for leg 4 , and the maximum normal force of the foot of leg 6 varies from augmentation to a decrease.

\subsection{Theoretical Analysis of Normal Force of Foot under Crab-type Tripod Gait}

The robot in support phase is shown in Figure 12, when the crab-type tripod gait is employed for the heavy-duty six-legged robot. As shown in Figure 12, the robot walks along the $X_{\mathrm{B}}$ axis in the body coordinate system.

Based on Figure 12, the feet's coordinates in the support phase can be obtained along the $y$ direction of the body coordinate system $\sum_{\mathrm{B}}$. Then

$$
\left\{\begin{array}{l}
{ }^{\mathrm{B}} P_{\mathrm{Fy}}^{\left(s_{2}\right)}=0, \\
{ }^{\mathrm{B}} P_{\mathrm{F} y}^{\left(s_{4}\right)}=-\left(r_{\mathrm{bp}} \sin 60^{\circ}+L_{\mathrm{P} 4}^{\prime} \sin \left(\Delta \theta_{4}\right)\right), \\
{ }^{\mathrm{B}} P_{\mathrm{F} y}^{\left(s_{6}\right)}=\left(r_{\mathrm{bp}} \sin 60^{\circ}+L_{\mathrm{P} 6}^{\prime} \sin \left(\Delta \theta_{6}\right)\right) .
\end{array}\right.
$$




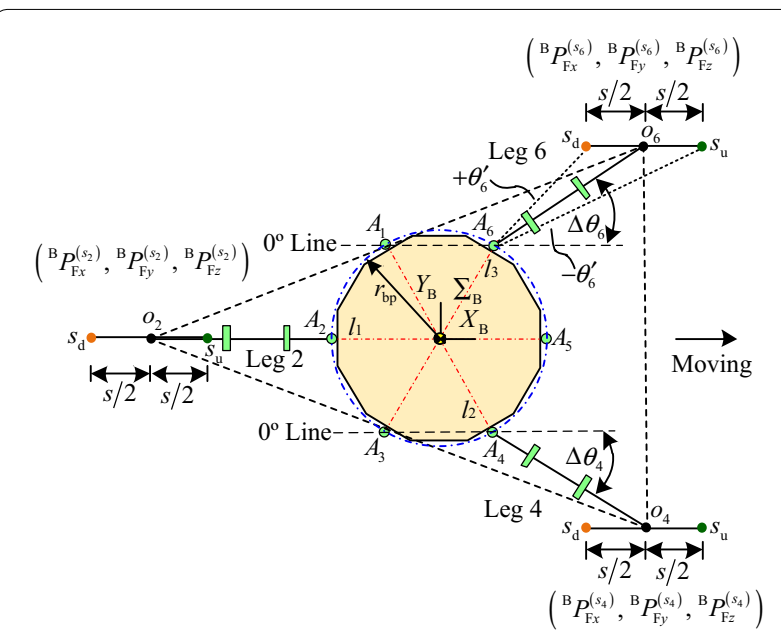

Figure 12 Support phase of heavy-duty six-legged under crab-type tripod gait

When the body of the robot walks forward with a step pitch $s$, the foot of the leg in support phase relatively moves back a distance $s$. That is to say, the support points of the legs respectively move from the upper point $s_{\mathrm{u}}$ to the lower point $s_{\mathrm{d}}$. Then, the coordinates of the feet at the lower point $s_{\mathrm{d}}$ can be respectively obtained along the $x$ direction in the body coordinate system $\sum_{\mathrm{B}}$ for legs 2,4 , and 6; they are shown as follows:

$$
\left\{\begin{array}{l}
{ }^{\mathrm{B}} P_{\mathrm{F} x}^{\left(s_{2}\right)}=-\left(r_{\mathrm{bp}}+L_{\mathrm{P} 2}^{\prime}\right)-\frac{s}{2}, \\
{ }^{\mathrm{B}} P_{\mathrm{F} x}^{\left(s_{4}\right)}=r_{\mathrm{bp}} \cos 60^{\circ}+L_{\mathrm{P} 4}^{\prime} \cos \left(\Delta \theta_{4}\right)-\frac{s}{2}, \\
{ }^{\mathrm{B}} P_{\mathrm{F} x}^{\left(s_{6}\right)}=r_{\mathrm{bp}} \cos 60^{\circ}+L_{\mathrm{P} 6}^{\prime} \cos \left(\Delta \theta_{6}\right)-\frac{s}{2} .
\end{array}\right.
$$

Equations (17) and (18) can be substituted into Eq. (12), and the mathematical models of the normal forces of the feet can be respectively deduced for legs 2,4 , and 6 . Then

$$
\left\{\begin{array}{l}
{ }^{\mathrm{B}} F_{z}^{\left(s_{2}\right)}=\frac{\left(r_{\mathrm{bp}}+2 L_{\mathrm{PS}}^{\prime} \cos (\Delta \theta)-s\right)\left(m_{\mathrm{L}} g+m_{\mathrm{R}} g\right)}{3 r_{\mathrm{bP}}+2 L_{\mathrm{PS}}^{\prime}+2 L_{\mathrm{PS}}^{\prime} \cos (\Delta \theta)}, \\
{ }^{\mathrm{B}} F_{z}^{\left(s_{4}\right)}=\frac{\left(r_{\mathrm{bp}}+L_{\mathrm{PS}}^{\prime}+s / 2\right)\left(m_{\mathrm{L}} g+m_{\mathrm{R}} g\right)}{3 r_{\mathrm{bp}}+2 L_{\mathrm{PS}}^{\prime}+2 L_{\mathrm{PS}}^{\prime} \cos (\Delta \theta)}, \\
{ }^{\mathrm{B}} F_{z}^{\left(s_{6}\right)}=\frac{\left(r_{\mathrm{bp}}+L_{\mathrm{PS}}^{\prime}+s / 2\right)\left(m_{\mathrm{L}} g+m_{\mathrm{R}} g\right)}{3 r_{\mathrm{bp}}+2 L_{\mathrm{PS}}^{\prime}+2 L_{\mathrm{PS}}^{\prime} \cos (\Delta \theta)} .
\end{array}\right.
$$

When the feet in support phase for legs 2, 4, and 6 are located at the upper point $s_{\mathrm{u}}$, their coordinates along the $x$ direction in the body coordinate $\sum_{\mathrm{B}}$ can be obtained with changing $s$ to $-s$ in Eq. (18), and their normal forces of the feet can be also obtained by setting $s$ to $-s$ in Eq. (19). In addition, the mathematical models of the normal forces of the feet are not given for legs 2, 4, and 6 in this paper. Based on Eq. (19), it can be found that the normal

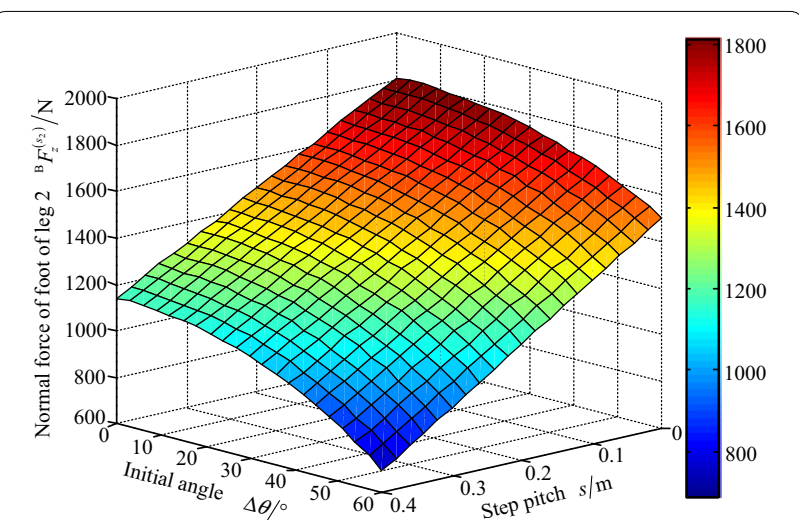

Figure 13 Variable tendency chart of normal force of foot for leg 2 with changes in $\Delta \theta$ and $s$ under crab-type tripod gait

force of the foot of leg 4 is equal to the normal force of the foot of leg 6 under the crab-type tripod gait.

The step pitch $s$, height $h$ of the body, and initial offset $L_{\text {PS }}^{\prime}$ are respectively set by $0.4 \mathrm{~m}, 0.5 \mathrm{~m}$, and $0.68 \mathrm{~m}$ for the heavy-duty six-legged robot, when the feet in support phase move from the upper point $s_{\mathrm{u}}$ to the lower point $s_{\mathrm{d}}$. The ranges of the initial angles of abductor joints are from $0^{\circ}$ to $60^{\circ}$ for legs $1,3,4$, and 6 . The radius $r_{\mathrm{bp}}$ of body is introduced into Eq. (19). Then, the MATLAB software is employed to analyze the normal forces of the feet in the support phase under the ant-type tripod gait. The variable tendency charts of the normal forces of the feet are obtained and respectively shown in Figures 13 and 14 for legs 2, 4, and 6.

Based on Figures 13 and 14, the curves of the maximum normal forces of feet are respectively obtained for legs 2 , 4 , and 6 with the initial angle $\Delta \theta$ and step pitch $s$ varying. When $s=0.2 \mathrm{~m}$ and $0^{\circ} \leq \Delta \theta \leq 60^{\circ}$, the curves of the maximum normal forces of feet are shown in Figure 15. When $0.05 \mathrm{~m} \leq s \leq 0.2 \mathrm{~m}$ and $\Delta \theta=0^{\circ}$, the curves of the maximum normal forces of feet are shown in Figure 16. When $0.1 \mathrm{~m} \leq s \leq 0.4 \mathrm{~m}$ and $\Delta \theta=60^{\circ}$, the curves of the maximum normal forces of feet are shown in Figure 17.

Based on Figure 13, it shows that the normal force of the foot decreases for leg 2 , when the step pitch $s$ is a fixed value and the range of initial angle $\Delta \theta$ is from $0^{\circ}$ to $60^{\circ}$, or when the initial angle $\Delta \theta$ is a fixed value and the range of step pitch $s$ is from $0 \mathrm{~m}$ to $0.4 \mathrm{~m}$. The foot's maximum normal force of leg 2 is $1814 \mathrm{~N}$, when the step pitch $s$ and the initial angle $\Delta \theta$ are $0 \mathrm{~m}$ and $0^{\circ}$, respectively. The foot's minimum normal force of leg 2 is $691.1 \mathrm{~N}$, when the step pitch $s$ is $0.4 \mathrm{~m}$ and the initial angle $\Delta \theta$ is $60^{\circ}$. The foot's normal force for leg 2 is $1098 \mathrm{~N}$, when the step pitch $s$ is $0 \mathrm{~m}$ and the initial angle $\Delta \theta$ is $60^{\circ}$.

Based on Figure 14, it shows that the normal forces of legs 4 and 6 increase, when the step pitch $s$ is a fixed value 


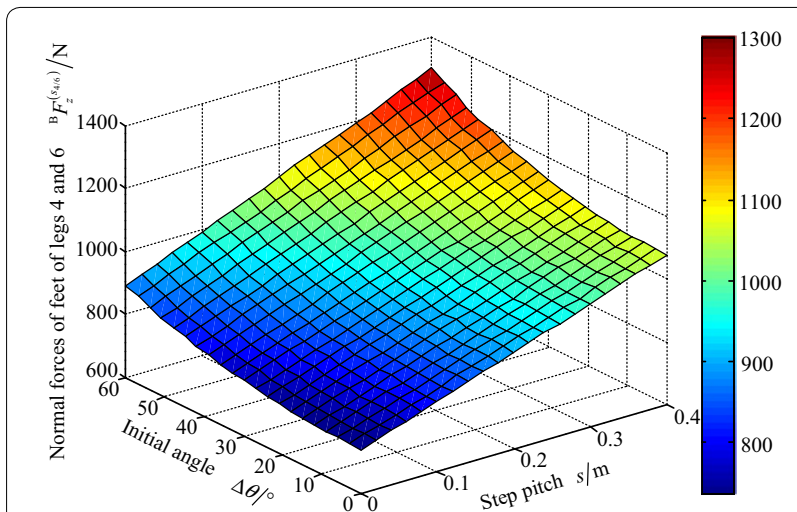

Figure 14 Variable tendency charts of normal forces of feet for legs 4 and 6 with changes in $\Delta \theta$ and $s$ under crab-type tripod gait

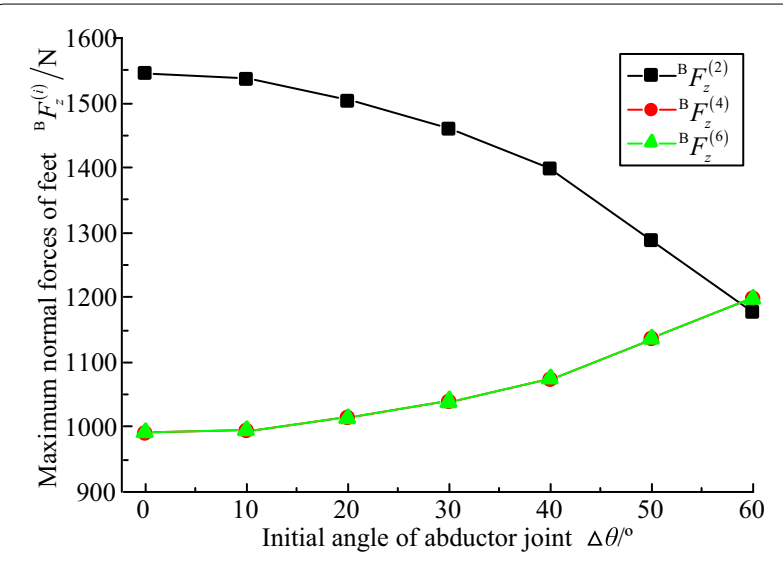

Figure 15 Curves of maximum normal forces of feet under $s=0.2 \mathrm{~m}$, $0^{\circ} \leq \Delta \theta \leq 60^{\circ}$, and crab-type tripod gait

and the range of initial angle $\Delta \theta$ is from $0^{\circ}$ to $60^{\circ}$, or when the initial angle $\Delta \theta$ is a fixed value and the range of step pitch $s$ is from $0 \mathrm{~m}$ to $0.4 \mathrm{~m}$. The minimum normal forces of feet are $739.2 \mathrm{~N}$ for leg 4 and leg 6 , when the step pitch $s$ and initial angle $\Delta \theta$ are $0 \mathrm{~m}$ and $0^{\circ}$, respectively. The maximum normal forces of feet are $1301 \mathrm{~N}$, when the step pitch $s$ is $0.4 \mathrm{~m}$ and the initial angle $\Delta \theta$ is $60^{\circ}$. The normal forces of feet are $1098 \mathrm{~N}$ for leg 4 and leg 6, when the step pitch $s$ is $0 \mathrm{~m}$ and the initial angle $\Delta \theta$ is $60^{\circ}$.

Based on Figure 15, when the step pitch $s$ is $0.2 \mathrm{~m}$ and the initial angle $\Delta \theta$ varies from $0^{\circ}$ to $60^{\circ}$, it shows that the maximum normal force of the foot gradually decreases for leg 2, and gradually increases for leg 4 and leg 6 , respectively. The maximum normal forces of the feet are equal to each other for legs 2,4 , and 6 , when the initial angle $\Delta \theta$ is $60^{\circ}$.

According to Figure 16, when the initial angle $\Delta \theta$ is $0^{\circ}$ and the step pitch $s$ varies from $0.05 \mathrm{~m}$ to $0.2 \mathrm{~m}$, it shows that the maximum normal forces of feet gradually increase

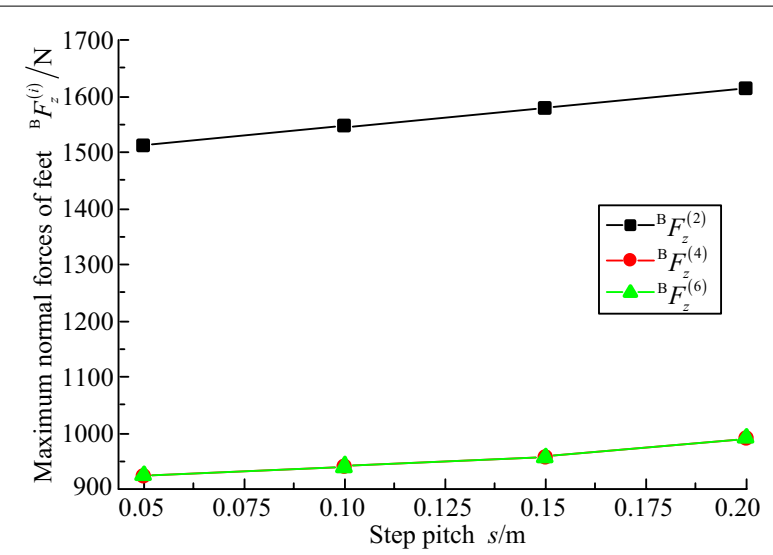

Figure 16 Curves of maximum normal forces of feet under $0.05 m \leq s \leq 0.2 m, \Delta \theta=0^{\circ}$, crab-type tripod gait

for legs 2,4 , and 6 . And the curves of the maximum normal forces of the feet are the same for leg 4 and leg 6 .

Based on Figure 17, when the initial angle $\Delta \theta$ is $60^{\circ}$ and the step pitch $s$ varies from $0.1 \mathrm{~m}$ to $0.4 \mathrm{~m}$, it can be concluded that the variable tendency of the maximum normal force of the foot augments then decreases for leg 2 . And the maximum normal forces of the feet are equal and gradually increase with the change of the step pitch for leg 4 and leg 6 .

\section{Force Experimental Analysis of Foot under Robotic Gait}

Based on the previous achievements in the scientific research, the prototype of electrically driven heavy-duty six-legged robot was developed. Its load to mass ratio is more than 0.46 . The walking experiments of prototype are implemented under four kinds of typical tripod gaits on a flat ground. In addition, the walking experiments of the mixture-type II walking mode are shown in Figure 18. The force experimental analysis of the foot is not

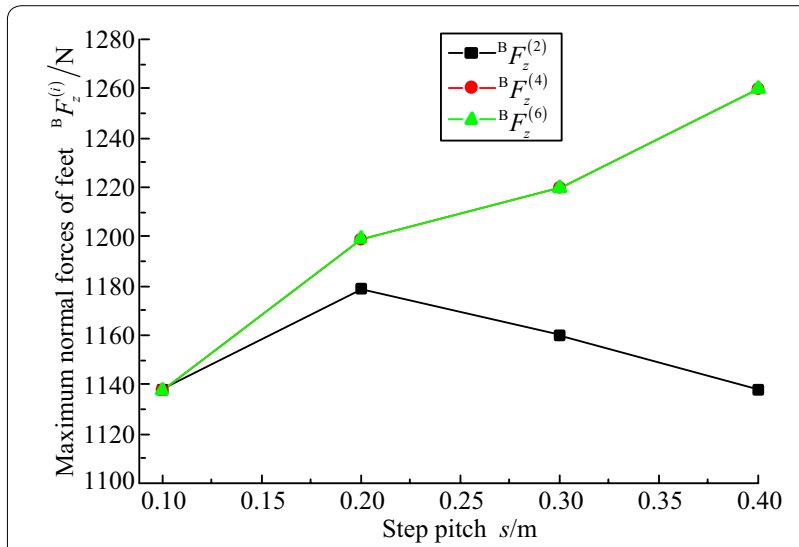

Figure 17 Curves of maximum normal forces of feet under $0.1 \mathrm{~m} \leq s \leq 0.4 \mathrm{~m}, \Delta \theta=60^{\circ}$, crab-type tripod gait 


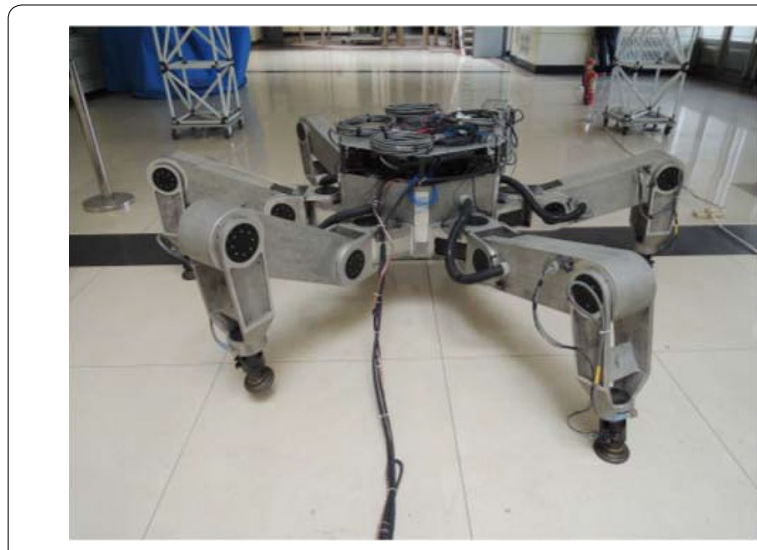

Figure 18 Walking experiments of mixture-type II walking mode

only able to verify the correctness of the force theoretical analysis, but is also helpful to further analyze the relations between the gait and the normal force of feet.

Three walking periods are respectively set for the heavyduty six-legged robot in walking experiments of the tripod gait. The six-dimension force/torque sensors are employed to collect the normal forces of the feet for all six legs in real time, and the maximum normal forces of the feet are collected for every leg. The curves of the maximum normal forces of the feet for the six legs are respectively obtained with the change in the step pitch and initial angle of the abductor joint. While the experimental and theoretical results of the variable tendencies of the maximum normal forces are the same, it can be concluded that the experimental data is correct, and the theoretical analysis is reasonable. When the four kinds of typical tripod gaits are used for the walking experiments, the initial offset $L_{\mathrm{p} i}^{\prime}$ is set by $0.68 \mathrm{~m}$, and the mass $m_{\mathrm{R}}$ of cargo is set by $0 \mathrm{~kg}$.

\subsection{Force Experimental Analysis of Foot under Ant-type Tripod Gait}

\subsubsection{Changing Initial Angle}

When the heavy-duty six-legged robot walks along the $Y_{\mathrm{B}}$ direction in the body coordinate system under the anttype tripod gait, the initial angles of abductor joints vary from $20^{\circ}$ to $60^{\circ}$ for legs $1,3,4$, and 6 , and the initial angles are $0^{\circ}$ for leg 2 and leg 5 . In addition, the body height $h$ and step pitch $s$ are $0.5 \mathrm{~m}$ and $0.3 \mathrm{~m}$, respectively. The variable tendency of the maximum normal force ${ }^{\mathrm{B}} F_{z}^{(i)}$ of the foot of leg $i$ can be obtained with the change in the initial angle, as shown in Figure 19.

Figure 19 shows that the maximum normal forces for the feet of leg 2 and leg 5 gradually decrease with the change in the initial angle, and their variable tendencies are equal. When the initial angle is $20^{\circ}$, the maximum normal forces of the feet for leg 2 and leg 5 are larger than the other maximum normal forces of the feet. When the

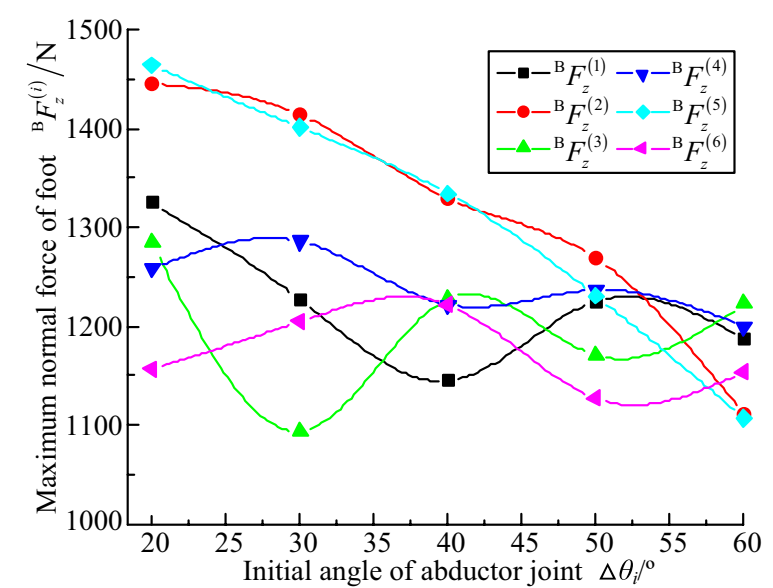

Figure 19 Variable tendencies of maximum normal forces of feet with change in initial angle under ant-type tripod gait

initial angle is $60^{\circ}$, the minimum difference exists among the maximum normal forces of the feet. Based on Figures 9 and 19, it is concluded that the variable tendencies of the feet's maximum normal forces are respectively corresponding to the same for legs 2,4 , and 6 , when the step pitch is $0.3 \mathrm{~m}$ and the initial angle varies from $20^{\circ}$ to $60^{\circ}$.

\subsubsection{Changing Step Pitch}

Without losing the generality, the initial angles are set by $20^{\circ}$ for legs $1,3,4$, and 6 , and set by $0^{\circ}$ for leg 2 and leg 5 , when the heavy-duty six-legged robot walks along the $Y_{\mathrm{B}}$ direction in the body coordinate system under the ant-type tripod gait. In addition, the body height $h$ keeps $0.5 \mathrm{~m}$, and the step pitch $s$ varies from $0.1 \mathrm{~m}$ to $0.4 \mathrm{~m}$. The variable tendency of the maximum normal force ${ }^{\mathrm{B}} F_{z}^{(i)}$ of the foot of leg $i$ can be obtained with the change in the step pitch, as shown in Figure 20.

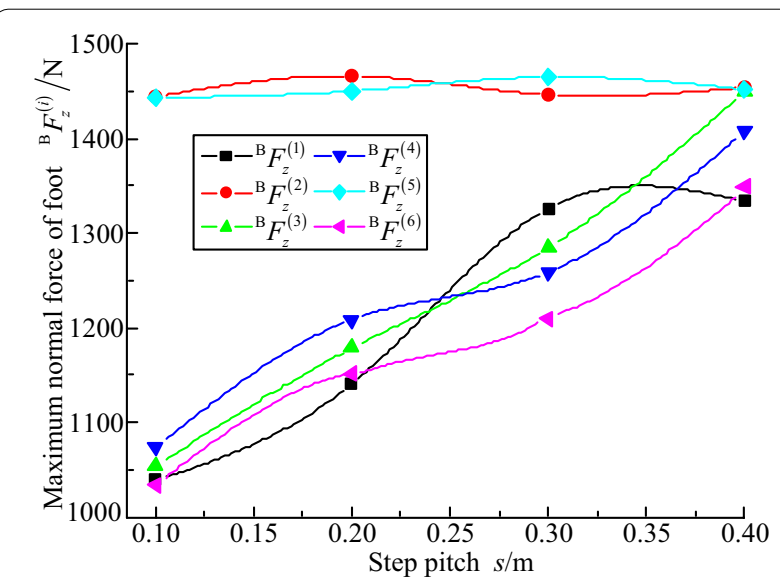

Figure $\mathbf{2 0}$ Variable tendencies of maximum normal forces of feet with change in step pitch under ant-type tripod gait 
Based on Figure 20, with the step pitch varying from $0.1 \mathrm{~m}$ to $0.4 \mathrm{~m}$, it is concluded that the curves of the maximum normal forces of feet keep stable for leg 2 and leg 5, and they are over other curves. According to Figure 20, it can be found that the force distribution is easier to realize when the step pitch has a larger value. Based on Figures 10 and 20, it can also be concluded that the variable tendencies of the maximum normal forces of the feet are respectively corresponding to the same for legs 2,4 , and 6 , when the initial angle is $20^{\circ}$ and the step pitch varies from $0.1 \mathrm{~m}$ to $0.4 \mathrm{~m}$.

\subsection{Force Experimental Analysis of Foot under Crab-type Tripod Gait \\ 5.2.1 Changing Initial Angle}

When the heavy-duty six-legged robot walks along the $X_{\mathrm{B}}$ direction in the body coordinate system under the crab-type tripod gait, the initial angles of the abductor joints vary from $0^{\circ}$ to $60^{\circ}$ for legs $1,3,4$, and 6 , and the initial angles are $0^{\circ}$ for leg 2 and leg 5 . In addition, the body height $h$ and step pitch $s$ keep $0.5 \mathrm{~m}$ and $0.2 \mathrm{~m}$, respectively. The variable tendency of the maximum normal force ${ }^{\mathrm{B}} F_{z}^{(i)}$ of the foot of leg $i$ can be obtained with the change in the initial angle, as shown in Figure 21.

Based on Figure 21, it shows that the curves of the maximum normal forces of the feet present a gradually downward trend for leg 2 and leg 5, and gradually rising trends for the other legs, with the initial angle varying from $0^{\circ}$ to $60^{\circ}$. When the initial angle is in between $0^{\circ}$ and $50^{\circ}$, the maximum normal forces of the feet of leg 2 and leg 5 are greater than the maximum normal forces of the feet of other legs. The maximum normal forces of the feet are approximately equal to each other, when the initial angle is $60^{\circ}$. Based on Figures 15 and 21, it can be found that the variable tendencies of the maximum normal forces

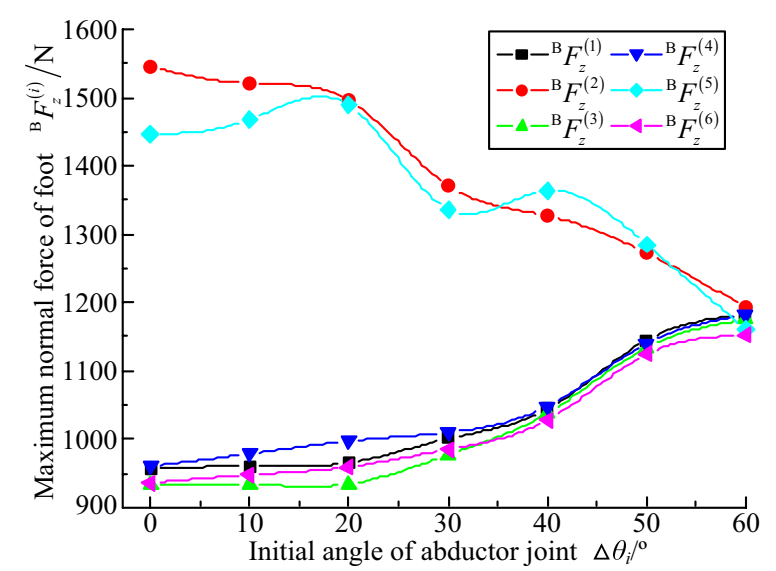

Figure 21 Variable tendencies of maximum normal forces of feet with change in initial angle under crab-type tripod gait of the feet are respectively corresponding to the same for legs 2,4 , and 6 , when the step pitch is $0.2 \mathrm{~m}$ and the initial angle varies from $0^{\circ}$ to $60^{\circ}$.

\subsubsection{Changing Step Pitch}

Without losing the generality, the initial angles are set by $0^{\circ}$ for legs $1,2,3,4,5$, and 6 , when the heavy-duty sixlegged robot walks with the ant-type tripod gait along the $X_{\mathrm{B}}$ direction in the body coordinate system. In addition, the body height $h$ keeps $0.5 \mathrm{~m}$, and the step pitch $s$ is between $0.05 \mathrm{~m}$ and $0.2 \mathrm{~m}$. The variable tendency of the maximum normal force ${ }^{\mathrm{B}} F_{z}^{(i)}$ of the foot of leg $i$ can be obtained with the change in the step pitch, as shown in Figure 22.

Based on Figure 22, with the step pitch varying from $0.05 \mathrm{~m}$ to $0.2 \mathrm{~m}$, it can be concluded that the curves of the maximum normal forces of the feet are mostly uniform for leg 2 and leg 5, for leg 3 and leg 4, and for leg 2 and leg 5, respectively. Meanwhile, the maximum normal forces of leg 2 and leg 5 are greater than other legs' maximum normal forces. Figure 22 shows that the maximum normal forces of the feet gradually increase with the step pitch varying for legs 1, 2, 3, 4, and 6. Based on Figures 16 and 22 , it can be concluded that the variable tendencies of maximum normal forces of the feet are respectively corresponding to the same for legs 2,4 , and 6 , when the initial angle is $0^{\circ}$ and the step pitch varies from $0.05 \mathrm{~m}$ to $0.2 \mathrm{~m}$.

\subsection{Force Experimental Analysis of Foot under Mixture-type I Tripod Gait}

When the heavy-duty six-legged robot walks using the mixture-type I tripod gait along the $X_{\mathrm{B}}$ direction in the body coordinate system, the initial angles are all $60^{\circ}$ for

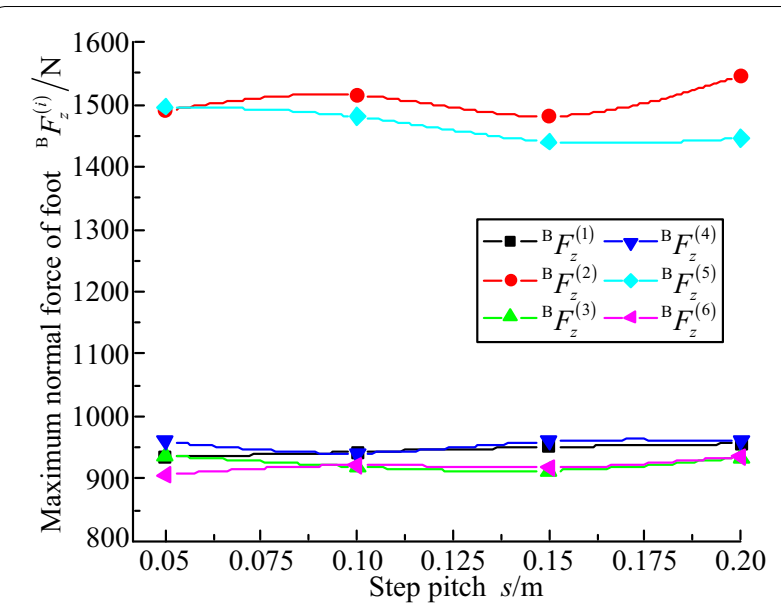

Figure 22 Variable tendencies of maximum normal forces of feet with change in step pitch under crab-type tripod gait 


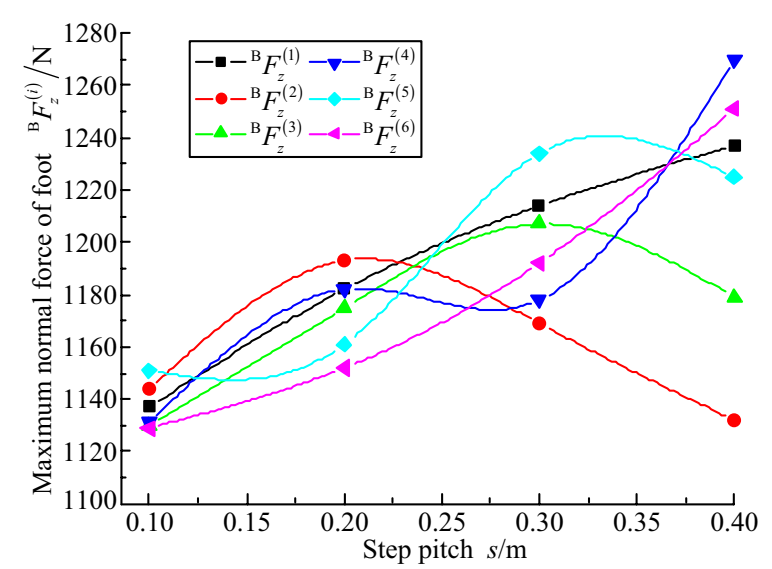

Figure 23 Variable tendencies of maximum normal forces of feet with change in step pitch under mixture-type I tripod gait

legs $1,3,4$, and 6 , and initial angles are all $0^{\circ}$ for leg 2 and leg 5 . In addition, the body height $h$ keeps $0.5 \mathrm{~m}$, and the step pitch $s$ ranges between $0.1 \mathrm{~m}$ and $0.4 \mathrm{~m}$. The variable tendency of the maximum normal force ${ }^{\mathrm{B}} F_{z}^{(i)}$ of the foot of leg $i$ can be obtained with the change in the step pitch, as shown in Figure 23.

Based on Figure 23, it can be concluded that the deviations of maximum normal forces of the feet become larger with the step pitch increasing from $0.1 \mathrm{~m}$ to $0.4 \mathrm{~m}$. According to Figures 17 and 23, it can be found that the variable tendencies of maximum normal forces of the feet correspond uniformly for legs 2, 4, and 6, respectively, when the initial angle is $60^{\circ}$ and the step pitch ranges between $0.1 \mathrm{~m}$ to $0.4 \mathrm{~m}$.

\subsection{Force Experimental Analysis of Foot under Mixture-type II Tripod Gait}

When the heavy-duty six-legged robot walks using the mixture-type II tripod gait along the $Y_{\mathrm{B}}$ direction in body coordinate system, the initial angles are all $60^{\circ}$ for legs 1 , 3,4 , and 6 , and initial angles are all $0^{\circ}$ for leg 2 and leg 5 . In addition, the body height $h$ keeps $0.5 \mathrm{~m}$, and the step pitch $s$ ranges between $0.1 \mathrm{~m}$ and $0.4 \mathrm{~m}$. The variable tendency of the maximum normal force ${ }^{\mathrm{B}} F_{z}^{(i)}$ of foot of leg $i$ can be obtained with the change in the step pitch, as shown in Figure 24.

Based on Figure 24, with the step pitch ranging from $0.1 \mathrm{~m}$ to $0.4 \mathrm{~m}$, it can be concluded that the curve of the maximum normal force of the foot approximately keeps stable for leg 2. The variable tendency of the maximum normal force of foot presents from decrease to augmentation for leg 4; the variable tendency shows adverse to leg 6's. According to Figures 11 and 24, it can be found that the variable tendencies of the maximum normal forces of the feet are respectively corresponding to the

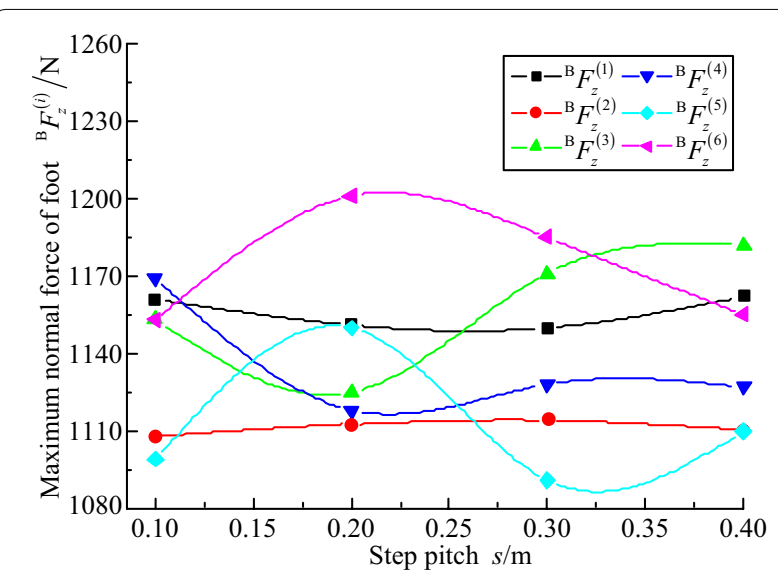

Figure 24 Variable tendencies of maximum normal forces of feet with change in step pitch under mixture-type II tripod gait

same for legs 2,4 , and 6 , when the initial angle is $60^{\circ}$ and the step pitch ranges between $0.1 \mathrm{~m}$ to $0.4 \mathrm{~m}$.

\subsection{Amplitude Interval Analysis of Normal Force of Foot under Gait of Robot}

Based on the analysis above, it can be obtained that the results of theoretical and experimental data keep consistent in the aspect of the maximum normal force of the foot. Hence, it can be concluded that the reasonableness and correctness can be respectively obtained for the force theoretical analysis of the foot and experimental data under four kinds of typical tripod gaits of heavy-duty sixlegged robots.

To further analyze the characteristics of normal forces of the feet, the range of maximum normal force of the foot is defined, it is a difference between the maximum value and the minimum value in the figure, and its symbol is set as $R_{\mathrm{F}}$. Based on Figures 19, 20, 21, 22, 23, and 24 , the ranges of maximum normal forces of the feet are respectively obtained under four kinds of typical tripod gaits, as shown in Table 1. Which the range of maximum normal force of the foot is the least among the walking modes, it can be found that the force distribution is the most easily achieved under that walking mode.

Based on Table 1, it is concluded that the mixturetype I has the least range of maximum normal force of the foot. In the aspect of force distribution, it can be obtained that the ant-type tripod gait is better than the crab-type tripod gait, and the mixture-type I tripod gait is better than the mixture-type II tripod gait. Therefore, the hexapod mostly chooses the ant-type walking mode rather than the crab-type walking mode.

According to Figure 4, it can be found that the walking speed of the heavy-duty six-legged robot depends on the hip joints and knee joints of leg 2 and leg 5, not 
Table 1 Ranges of maximum normal forces of feet under four kinds of typical tripod gaits

\begin{tabular}{lll}
\hline Walking modes & \multicolumn{2}{l}{$\begin{array}{l}\text { Ranges of maximum normal forces } \\
\text { of feet } \boldsymbol{R}_{\mathbf{F}} / \mathbf{N}\end{array}$} \\
\cline { 2 - 3 } Change in initial angle & $\begin{array}{l}\text { Change } \\
\text { in step } \\
\text { pitch }\end{array}$ \\
\hline Ant type & 370 & 432 \\
Crab type & 614.5 & 638.4 \\
Mixture type I & - & 141 \\
Mixture type II & - & 157 \\
\hline
\end{tabular}

on their abductor joints. When the actuating devices are confirmed and need to provide large torque, the hip joints and knee joints of leg 2 and leg 5 limits the walking speed of the robot. Hence, the mixture-type II walking mode is better than the mixture-type I walking mode in the aspect of walking speed.

Based on the analysis above, it can be concluded that the mixture-type I and mixture-type II walking modes are better than the ant type and crab type in the aspect of the force distribution and stability. Furthermore, it can be obtained that the mixture-type II walking mode is the best and should be preferentially employed for the heavy-duty six-legged robot with the consideration of walking speed. Actually, the reasonable walking mode can be used based on the practical requirements of the heavy-duty six-legged robot, and it can be concluded that the maximum walking speed of robot is easily achieved by the ant-type walking mode. The limited space can be traversed using the crab-type walking mode. The force distribution and stability can be easily realized using the mixture-type I walking mode and mixture-type II walking mode.

\section{Conclusions}

(1) Four kinds of typical walking modes are obtained based on the configuration of root. The variable tendency charts of normal forces of the feet are described with the changes in the initial angle and step pitch by performing the theoretical analysis of static foot force.

(2) According to the walking experiments of robot prototype under four kinds of typical tripod gaits, the variable tendencies of the maximum normal forces of feet are respectively obtained with the changes in the initial angle and step pitch. The comparison results show that the theoretical and experimental data are in the same trend under the same variable and same walking mode of the tripod gait.
(3) The optimal walking mode, the mixture-type II walking mode, is confirmed, and it is firstly recommended for the electrically driven heavy-duty six-legged robot in view of its excellent characteristics in walking speed, stability, force distribution, and load to mass ratio.

\section{Additional file}

Additional file 1: Brief introduction of the article.

\section{Authors' Contributions}

$\mathrm{ZL}$ and $\mathrm{H}-\mathrm{CZ}$ was in charge of the whole trial; $\mathrm{H}-\mathrm{CZ}$ wrote the manuscript; $\mathrm{H}-\mathrm{CZ}, \mathrm{H}-\mathrm{BG}, \mathrm{Z}-\mathrm{QD}$, and LD assisted with sampling and laboratory analyses. All authors read and approved the final manuscript.

\section{Author details}

1 State Key Laboratory of Robotics and System, Harbin Institute of Technology, Harbin 150080, China. ${ }^{2}$ College of Mechanical Engineering, Tianjin University of Technology and Education, Tianjin 300222, China.

\section{Authors' Information}

Zhen Liu, born in 1983, is currently a lecturer at State Key Laboratory of Robotics and System, Harbin Institute of Technology, China. He received his PhD degree from Harbin Institute of Technology, China, in 2013. His research interests

include planetary rover technology and aerospace mechanisms and control. Hong-Chao Zhuang, born in 1982, is currently a lecturer at College of Mechanical Engineering, Tianjin University of Technology and Education, China. He received his PhD degree from Harbin Institute of Technology, China, in 2015. His research interests include special robot systems and intelligent robotics.

Hai-Bo Gao, born in 1970, is currently a professor and a supervisor for PhD candidates at State Key Laboratory of Robotics and System, Harbin Institute of Technology, China. He received his PhD degree from Harbin Institute of Technology, China, in 2004. His research interests include special robot systems and aerospace mechanisms and control.

Zong-Quan Deng, born in 1956, is currently a professor and a supervisor for PhD candidates at Harbin Institute of Technology, China. He received his master's degree from Harbin Institute of Technology, China, in 1984. His research interests include planetary rover technology and aerospace mechanisms and control.

Liang Ding, born in 1980, is currently a professor and a supervisor for PhD candidates at State Key Laboratory of Robotics and System, Harbin Institute of Technology, China. He received his PhD degree from Harbin Institute of Technology, China, in 2009. His research interests include planetary rover technology and aerospace mechanisms and control.

\section{Competing Interests}

The authors declare no competing financial interests.

\section{Funding}

Supported by National Natural Science Foundation of China (Grant Nos. $51505335,51275106)$, and National Basic Research Program of China (973 Program, Grant No. 2013CB035502).

\section{Publisher's Note}

Springer Nature remains neutral with regard to jurisdictional claims in published maps and institutional affiliations.

Received: 1 August 2016 Accepted: 2 August 2018

Published online: 14 August 2018 


\section{References}

[1] T Koolen, S Bertrand, G Thomas, et al. Design of a momentum-based control framework and application to the humanoid robot Atlas. International Journal of Humanoid Robotics, 2016, 13(1): 1-35.

[2] K Nozaki, T Murakami. A motion control of two-wheels driven mobile manipulator for human-robot cooperative transportation. Proceedings of the 35th Annual Conference of the IEEE Industrial Electronics Society, IECON 2009, Porto, Portugal, November 3-5, 2009: 1574-1579.

[3] M Eich, F Grimminger, F Kirchner. Adaptive compliance control of a multilegged stair-climbing robot based on proprioceptive data. Industrial Robot, 2009, 36(4): 331-339.

[4] B L Luk, D S Cooke, S Galt, et al. Intelligent legged climbing service robot for remote maintenance applications in hazardous environments. Robotics and Autonomous Systems, 2005, 53(2): 142-152.

[5] B H Wilcox, T E Litwin, J J Biesiadecki, et al. ATHLETE: A cargo handling and manipulation robot for the moon. Journal of Field Robotics, 2007, 24(5): 421-434

[6] TTsumaki, H Kobayashi, E Nakano, et al. Development of a practically scaled walking robot for steep terrain of forestry ground. Journal of the Robotics Society of Japan, 2009, 27(4): 470-480.

[7] S Nakajima. Concept of a novel four-wheel-type mobile robot for rough terrain, RT-mover. Proceedings of the IEEE/RSJ International Conference on Intelligent Robots and Systems, IROS 2009, St. Louis, MO, United States, October 11-15, 2009: 3257-3264.

[8] B Gamann, F Zacharias, J M Zöllner, et al. Localization of walking robots. Proceedings of the IEEE International Conference on Robotics and Automation, Barcelona, Spain, April 18-22, 2005: 1471-1476.

[9] D Wooden, M Malchano, K Blankespoor, et al. Autonomous Navigation for BigDog. Proceedings of the IEEE International Conference on Robotics and Automation, Anchorage, Alaska, USA, May 3-7, 2010: 4736-4741.

[10] E P Krotkov, R G Simmons, W L Whittaker. Ambler: Performance of a sixlegged planetary rover. Acra Asrronaurrca, 1995, 35(1): 75-81.

[11] V Sunspiral, D W Wheeler, D Chavez-Clemente, et al. Development and field testing of the footfall planning system for the ATHLETE robots. Journal of Field Robotics, 2012, 29(3): 483-505.

[12] F Tedeschi, G Carbone. Design issues for hexapod walking robots. Robotics, 2014, 3(2): 181-206.

[13] J E Bares, D S Wettergreen. Dante II: Technical description, results, and lessons learned. The International Journal of Robotics Research, 1999, 18(7): 621-649.

[14] H C Zhuang, H B Gao, Z Q Deng, et al. A review of heavy-duty legged robots. Science China Technological Sciences, 2014, 57(2): 298-314.

[15] H C Zhuang, H B Gao, Z Q Deng. Gait planning research for an electrically driven large-load-ratio six-legged robot. Applied Sciences-Basel, 2017, 7(3), 296: 1-17.
[16] J M Yang. Tripod gaits for fault tolerance of hexapod walking machines with a locked joint failure. Robotics and Autonomous Systems, 2005, 52(2-3): 180-189.

[17] H Q Liu, Y B Liu, H Zhang, et al. Posture control strategy based on force distribution for bionic six-legged robot. Journal of Harbin University of Commerce (Natural Sciences Edition), 2012, 28(5): 541-545. (in Chinese)

[18] H C Zhuang, H B Gao, Z Q Deng. Analysis method of articulated torque of heavy-duty six-legged robot under its quadrangular gait. Applied Sciences-Basel, 2016, 6(11), 323:1-21.

[19] Z J Li, S T Xiao, S Z S Ge, et al. Constrained multilegged robot system modeling and fuzzy control with uncertain kinematics and dynamics incorporating foot force optimization. IEEE Transactions on Systems, Man, and Cybernetics: Systems, 2016, 46(1): 1-15.

[20] WY Jiang, A M Liu, D Howard. Optimization of legged robot locomotion by control of foot-force distribution. Transactions of the Institute of Measurement and Control, 2004, 26(4): 311-323.

[21] WT Xi, C D Remy. Optimal gaits and motions for legged robots. Proceedings of the IEEE/RSJ International Conference on Intelligent Robots and Systems, IROS 2014, Chicago, IL, USA, September 14-18, 2014: 3259-3265.

[22] M Agheli, S S Nestinger. Study of the foot force stability margin for multilegged/wheeled robots under dynamic situations. Proceedings of the 8th IEEE/ASME International Conference on Mechatronic and Embedded Systems and Applications, MESA 2012, Suzhou, China, July 8-10, 2012: 99-104.

[23] A Elfes, R Steindl, F Talbot, et al. The multilegged autonomous explorer (MAX). Proceedings of the IEEE International Conference on Robotics and Automation (ICRA), Singapore, May 29-June 3, 2017: 1 050-1 057.

[24] H Montes, M Armada. Force control strategies in hydraulically actuated legged robots. International Journal of Advanced Robotic Systems, 2016, 13(2): $1-16$

[25] H B Gao, H C Zhuang, Z G Li, et al. Optimization and experimental research on a new-type short cylindrical cup-shaped harmonic reducer. Journal of Central South University of Technology, 2012, 19(7): 1869-1882.

[26] H C Zhuang, H B Gao, L Ding, et al. Method for analyzing articulated torques of heavy-duty six-legged robot. Chinese Journal of Mechanical Engineering, 2013, 26(4): 801-812.

[27] H C Zhuang, H B Gao, Z Q Deng, et al. Method for analyzing articulated rotating speeds of heavy-duty six-legged robot. Journal of Mechanical Engineering, 2013, 49(23): 44-52. (in Chinese)

[28] H B Gao, H C Zhuang, Z Q Deng, et al. Transmission mode research on the joints of a multi-legged walking robot. Applied Mechanics and Materials, 2012, 151: 518-522

\section{Submit your manuscript to a SpringerOpen ${ }^{\odot}$ journal and benefit from:}

- Convenient online submission

- Rigorous peer review

- Open access: articles freely available online

- High visibility within the field

- Retaining the copyright to your article

Submit your next manuscript at $\boldsymbol{\nabla}$ springeropen.com 